\title{
Respuestas educativas multinivel en educación secundaria para el alumnado con altas capacidades desde un enfoque inclusivo
}

\author{
Eva María Bailén Ferrández \\ Egresada del Máster Universitario en Formación del Profesorado de Educación Secundaria, \\ Bachillerato, Formación Profesional y Enseñanzas de Idiomas de la Universidad Rey Juan Carlos \\ eva.bailen@gmail.com
}

Este trabajo ha obtenido un Accésit del Premio Estudios Financieros 2019 en la modalidad de Educación y Nuevas Tecnologías.

El jurado ha estado compuesto por: doña Elena Faba de la Encarnación, doña Charo Fernández Aguirre, don Melchor Gómez García, doña Laura Rayón Rumayor y don Javier Soriano Camino.

Los trabajos se presentan con seudónimo y la selección se efectúa garantizando el anonimato de los autores.

\section{Extracto}

Según apuntan los expertos en altas capacidades (AA. CC.), un cociente intelectual (Cl) situado en el percentil 90 equivale a una puntuación de 120 en los test de inteligencia. A partir de este dato, y sabiendo que en España hay identificados solamente 25.000 alumnos de AA. CC., de un total de 8.000.000 de estudiantes escolarizados, podemos suponer que faltan muchos niños y jóvenes por detectar hasta llegar a los 800.000 alumnos con AA. CC. que supuestamente hay en nuestras aulas.

Las AA. CC. deben entenderse como un potencial, no como un valor de $\mathrm{Cl}$ que determina quién es de AA. CC. y quién no lo es, o quién se merece una educación que cultive su talento. Si en las aulas se utilizaran estrategias de desarrollo del talento para todos, no nos tendríamos que preocupar por identificar a los alumnos más capaces.

En esta investigación se realiza una propuesta de intervención en el aula, en formato de guía multinivel enriquecida, que trata de aunar las diferentes respuestas educativas reconocidas como adecuadas para los alumnos con AA. CC. desde un enfoque inclusivo. La guía multinivel permite flexibilizar contenidos, adaptarse a los diferentes ritmos de aprendizaje, incluso acelerar el ritmo si el estudiante lo reclama. También permite trabajar de manera creativa, despertar la motivación de los alumnos e introducir el aprendizaje basado en el pensamiento (thinking based learning $[\mathrm{TBL}])$.

Palabras clave: altas capacidades (AA. CC.); educación secundaria; inclusión educativa; instrucción multinivel; aprendizaje basado en el pensamiento (thinking based learning [TBL]); aceleración educativa; flexibilización educativa.

Fecha de entrada: 03-05-2019 / Fecha de aceptación: 15-07-2019

Cómo citar: Bailén Ferrández, E. M. ‥ (2020). Respuestas educativas multinivel en educación secundaria para el alumnado con altas capacidades desde un enfoque inclusivo. Tecnología, Ciencia y Educación, 15, 5-47. 


\title{
Multilevel solutions in secondary school for gifted students from an inclusive perspective
}

\author{
Eva María Bailén Ferrández
}

\begin{abstract}
According to experts in giftedness, an intelligence quotient located in the 90th percentile is equivalent to a score of 120 in the intelligence tests. From this data and knowing that in Spain there are only 25,000 gifted students identified, out of a total of $8,000,000$ students, we can assume that many children and teenagers have not been detected and the figure is still far from reaching the expected one of 800,000 that supposedly are in our classrooms.

Giftedness must be understood as a potential, not as an intelligence quotient value that determines who is and who is not, or who deserves an education that cultivates their talent. If talent development strategies were used in the classrooms for every student, we would not have to worry about identifying the most capable students.

In this research, a classroom intervention proposal is made, in the form of an enriched multilevel guide, which tries to combine the different educational responses recognized as suitable for gifted students from an inclusive approach. The multilevel guide allows flexible contents, the adaption to the different rhythms of learning, even to accelerate it if the student demands it. It also allows to work in a creative way, awaken students' motivation, and introduce thinking based learning (TBL).
\end{abstract}

Keywords: giftedness; secondary school; educational inclusion; multilevel instruction; thinking based learning (TBL); academic acceleration; academic flexibilization.

Citation: Bailén Ferrández, E. M.a. (2020). Multilevel solutions in secondary school for gifted students from an inclusive perspective. Tecnología, Ciencia y Educación, 15, 5-47. 


\section{Sumario}

1. Introducción

1.1. Justificación y valoración

1.2. Objetivos

2. Primera parte. Marco teórico

2.1. Inteligencia, creatividad, motivación y emoción

2.2. AA. CC. y talento

2.2.1. La atención de los alumnos con AA. CC.

2.2.2. La identificación de los alumnos con AA. CC.

2.3. Respuestas educativas

2.3.1. Respuestas educativas tradicionales para la atención de las AA. CC. Aceleración y enriquecimiento

2.3.2. Otras respuestas educativas para los alumnos con AA. CC.

2.4. La instrucción multinivel

3. Segunda parte. Aplicación práctica

3.1. Formación previa al diseño de la intervención. Metodología EBI. Requisitos de partida

3.2. Diseño de la propuesta de intervención. Elaboración de la guía multinivel enriquecida

3.3. Metodología de trabajo

3.4. Planificación (ejecución en el año 2018)

4. Tercera parte. Resultados y conclusiones

4.1. Resultados cualitativos y cuantitativos

4.2. Conclusiones y reflexiones personales

4.3. Limitaciones y futuras líneas de investigación

Referencias bibliográficas

Nota: este artículo es un extracto del trabajo fin de máster (TFM) elaborado por la autora como parte de los estudios del Máster Universitario en Formación del Profesorado de Educación Secundaria, Bachillerato, Formación Profesional y Enseñanzas de Idiomas (Especialidad Matemáticas), impartido en la Universidad Rey Juan Carlos durante el curso académico 2017-2018. La directora del TFM ha sido la profesora Raquel Garrido Abia. 


\section{Introducción}

\subsection{Justificación y valoración}

En este trabajo se desarrolla una investigación relacionada con la atención de los alumnos con AA. CC. intelectuales en las aulas de educación secundaria.

Dada la escasa formación del profesorado en cuanto a la detección, primero, y a la atención, después, de los alumnos superdotados, talentosos o con AA. CC., nos planteamos cómo podríamos contribuir a la mejora de la atención del alumnado con estas características desarrollando una investigación que ponga en práctica una serie de actuaciones en un aula diversa con el fin de mejorar la inclusión, la motivación y el aprendizaje de todos los alumnos, en general, y de los estudiantes con AA. CC., en particular.

Antes de avanzar más, es conveniente realizar una desambiguación de términos. Aunque muchas veces se usan indistintamente las acepciones «AA. CC.», «superdotación» $y$ «talento», lo cierto es que el término que mejor se ajusta es precisamente el de «AA. CC.», puesto que engloba y expresa mejor que ninguna otra definición la idea de potencialidad latente, evitando de alguna manera ideas preconcebidas heredadas de terminología menos apropiada. Así:

Aunque muchas veces se usan indistintamente las acepciones «AA. CC.», «superdotación» y «talento», lo cierto es que el término que mejor se ajusta es precisamente el de «AA. CC.», puesto que engloba y expresa mejor que ninguna otra definición la idea de potencialidad latente

El concepto de «AA. CC.» que introduce la Ley orgánica de educación (LOE), aunque no lo define, parece que ha sido bien acogido por ser un término más general que el de superdotación y reclama la atención también sobre los talentosos, los niños precoces, y por qué no, sobre todo aquel alumnado que está demostrando diariamente que puede manifestar conductas propias del alumnado bien dotado. También porque el punto fundamental, al hablar de AA. CC., es su carácter de potencialidad, frente a la exigencia de rendimiento recogido por otros conceptos y por la legislación educativa anterior (Comes, Díaz, Luque y Moliner, 2008, p. 105). 
Según los expertos (Marland, 1971), un porcentaje de la población, que varía entre el 3 y el $5 \%$, presenta AA. CC.; sin embargo, en España (Tourón, 2015), la cifra de alumnos detectados está muy lejos de llegar a dichos porcentajes.

Podría decirse que las respuestas educativas que tradicionalmente se han dado a los estudiantes más aventajados, es decir, la «aceleración» y el «enriquecimiento», entendido este último como el acto de proporcionar a los estudiantes más actividades, pero no necesariamente más creativas o ajustadas a sus capacidades, no cubren sus necesidades. Por ello, es importante encontrar otras soluciones que sí se ajusten a lo que los estudiantes con AA. CC. necesitan.

Por otra parte, las tasas de abandono escolar españolas son las más altas de la Organización para la Cooperación y el Desarrollo Económicos (OCDE), por lo que es necesario replantearse las metodologías que se usan en las aulas, ya que ni siquiera los alumnos más capaces quedan fuera de la amenaza del fracaso escolar.

Para iniciar esta investigación, reflexionamos sobre la cuestión a través del planteamiento de una serie de preguntas:

P1. ¿Necesitan alguna atención especial los alumnos más capaces?

P2. ¿Puede un alumno con AA. CC. fracasar en la escuela?

P3. ¿Qué ocurre con los niños bien dotados que no son atendidos correctamente?

P4. ¿Qué porcentaje de estudiantes con AA. CC. se detecta y qué porcentaje pasa desapercibido?

P5. ¿Se pueden detectar las AA. CC. en educación secundaria si no se ha hecho antes?

P6. ¿Se pueden perder las AA. CC. si no se identifican y potencian?

P7. ¿Son la aceleración y el enriquecimiento las mejores respuestas educativas para los alumnos con AA. CC.?

P8. ¿Cuáles son las respuestas educativas más adecuadas para atender a este tipo de alumnos?

P9. ¿Se puede responder a las necesidades educativas de estos alumnos desde la inclusión educativa?

P10. ¿Cómo se motiva a un alumno con AA. CC. para que su aprendizaje sea significativo?

P11. Teniendo en cuenta los aportes de la neurociencia, ¿cómo podemos, a la vez, responder a las necesidades de estos alumnos y avivar en ellos la curiosidad y la motivación por el aprendizaje? 
Podríamos pues formular el problema en una sola cuestión:

¿Existe una respuesta educativa válida para atender a los alumnos de educación secundaria con AA. CC. en un aula diversa?

Una valoración del problema planteado nos lleva a cuestionarnos varios puntos acerca del mismo:

- ¿Es resoluble? Sí, es resoluble. De hecho, en las escuelas de Canadá se lleva tiempo aplicando un tipo de instrucción llamada «multinivel», descrita por Collicot (1991), como respuesta a la atención a la diversidad, incluida la atención de las AA. CC.

- ¿Es real? Es un problema real, ya que muchos estudiantes con AA. CC. siguen sin ser detectados o sin ser atendidos correctamente en nuestro país, lo cual nos lleva a la pérdida de talento.

- ¿Es relevante? Sí, es un tema relevante, dada la importancia del desarrollo del talento para el crecimiento de un país. La creatividad y el talento son claves en el desarrollo económico. Si no detectamos a los más capaces y cultivamos su potencial, perdemos valor como sociedad.

- ¿Es factible? Partiendo de estudios y trabajos de diferentes autores, analizando experiencias previas y buscando respuestas en la neurociencia, podríamos encontrar alguna o varias soluciones.

- ¿Es generador de conocimiento? Sería muy revelador poder demostrar que la puesta en marcha de una respuesta educativa, como es la ya mencionada instrucción multinivel propuesta por Collicot (1991), lleva a una mejora en la atención de los alumnos con AA. CC.

- ¿Es generador de problemas? Más que generar nuevos problemas, la investigación aquí propuesta pone de manifiesto la necesidad ya reclamada por el colectivo de personas con AA. CC. de cambiar el paradigma educativo en lo que al desarrollo del talento, desde la detección hasta la correcta atención, se refiere. Con esta investigación se hace más evidente la necesidad de actuar, de cambiar la manera de enseñar y de abordar la instrucción de los alumnos más capaces. 


\subsection{Objetivos}

En cuanto a los objetivos de nuestro trabajo, podemos decir que se dividen en objetivos generales $(\mathrm{OG})$ y en objetivos específicos $(\mathrm{OE})$, planteándonos los siguientes:

- OG1. Encontrar una metodología educativa que permita a los profesores de educación secundaria atender a sus alumnos con AA. CC. en un aula inclusiva, teniendo además en cuenta los hallazgos de la neurociencia para propiciar así, por un lado, la inclusión educativa de estos alumnos, y, por otro lado, un aprendizaje significativo.

- OE1. Comprender las necesidades educativas de los estudiantes con AA. CC.

- OE2. Comparar las diferentes estrategias posibles para cubrir dichas necesidades.

- OE3. Comprobar si la metodología del aprendizaje multinivel propuesta por Collicot (1991) o los agrupamientos flexibles a los que se refiere Tomlinson (1999) impactan positivamente en el aprendizaje y la motivación de los estudiantes con AA. CC.

- OE4. Analizar las diferentes formas de atender a alumnos con AA. CC. y averiguar si alguna de ellas presenta ventajas claras respecto al resto.

\section{Primera parte. Marco teórico}

\subsection{Inteligencia, creatividad, motivación y emoción}

La inteligencia ha sido ampliamente estudiada por la comunidad científica y está sujeta a diferentes definiciones. Tanto Sternberg (1985a) como Gardner (2005) defienden que no existe un solo tipo de inteligencia. Además, no se puede hablar de la inteligencia sin incluir también la creatividad. Marina (1993) introduce en este sentido la teoría de la inteligencia creadora, además de la teoría de la inteligencia ejecutiva (Marina, 2012).

Para Sternberg y O'Hara (2005), la creatividad está íntimamente relacionada con el concepto de «inteligencia», de ahí que algunos autores se refieran a su propuesta con la expresión «Superdotación creativa» (López, Prieto y Hervás, 1998). Lejos de la concepción extendida que asocia creatividad principalmente al ámbito de la producción artística, esta se hace imprescindible en el estudio y en la definición de la inteligencia, las AA. CC. o la superdotación.

Así, para Sternberg (1985a), la inteligencia se define desde un enfoque triárquico, íntimamente relacionado con la creatividad, la cual, según el autor, implica aspectos sintéticos, analíticos y prácticos. 
Por otro lado, según la teoría de las inteligencias múltiples de Gardner (2005), existen ocho tipos de inteligencias:

- Verbal-lingüística.

- Lógico-matemática.

- Visual-espacial.

- Musical.
- Interpersonal.

- Intrapersonal.

- Naturalista.

- Corporal-cinestésica.

No obstante, algunos autores cuestionan el uso que se está dando a la teoría de las inteligencias múltiples en el mundo académico:

Ningún estudio neurocientífico ha demostrado la validez de la hipótesis de las inteligencias múltiples, lo cual no quita que a nivel psicológico pueda ayudar a entender la complejidad y la diversidad de la inteligencia humana (Bueno, 2017, p. 44).

De hecho, el propio Gardner (2003) reflexiona sobre el uso que en educación se está haciendo de su teoría de las inteligencias múltiples. Así, respecto al intento de enseñar todos los conceptos o materias usando todas las inteligencias, el autor señala que, aunque muchos temas se pueden enfocar de varios modos, no tiene sentido asumir que todos los conceptos se pueden abordar de tantas maneras diferentes como tipos de inteligencia existan. Señala que esto es un error y un desperdicio de tiempo y esfuerzo.

Sternberg y O’Hara (2005) definen creatividad e inteligencia en los siguientes términos:

La creatividad se ha definido como el proceso de dar a luz algo nuevo y útil a la vez. La inteligencia se define como la habilidad para adaptarse voluntariamente, para moldear o para seleccionar un entorno (p. 113).

La neurociencia también tiene algo que aportar al conocimiento de la creatividad. Según Bueno (2017), el pensamiento creativo produce la activación de zonas muy concretas del cerebro ubicadas en la corteza prefrontal. Incluso existen genes que condicionan el nivel de creatividad de un individuo.

Otros autores, como Renzulli (2004), añaden un tercer rasgo a las altas capacidades: la motivación. No es casualidad, ya que, tal y como apunta Bueno (2017), motivación y creatividad son dos de las palabras más utilizadas en educación. Sin motivación no puede haber apren- 
dizaje. La motivación se desencadena al ofrecer al alumno la posibilidad de enfrentarse a un reto o resolverlo. A los niños les cuesta menos buscar su propia motivación según crecen, consiguiendo hallar una motivación intrínseca, del mismo modo que cada vez les resulta más sencillo retrasar la obtención de una recompensa. De hecho, el placer y la motivación son gestionados por la misma parte del cerebro: el núcleo accumbens. Así, la creatividad práctica tiene tres componentes: experiencia, habilidad de pensamiento creativo y motivación (Bueno, 2017).

Sin embargo, para el superdotado, la motivación es intrínseca (De Mirandés, 2001). Si se le facilitan al estudiante superdotado los medios para que investigue, para que realice un aprendizaje por descubrimiento (Bruner, 1974), autorregulando su propio proceso de aprendizaje, la motivación surgirá por sí sola.

Para acabar con lo relativo a la inteligencia, no podemos olvidar la importancia de las emociones, ya que estas han penetrado en el terreno de la inteligencia gracias a la idea de inteligencia emocional de Goleman (1995). Martín y Vargas (2014) incluyen entre las características de los niños con AA. CC. la intensidad para sentir emociones, de ahí la importancia de la inteligencia emocional cuando se habla de AA. CC.

Según Salovey y Mayer (1990), recogido en Bisquerra y Pérez (2007), la inteligencia emocional es la habilidad para manejar los sentimientos y las emociones, discriminar entre ellos y usar dicho conocimiento para dirigir los propios pensamientos y acciones. Estos autores, en sucesivas aportaciones, han ido reformulando el concepto (Mayer, Caruso y Salovey, 1999, 2000, 2004, 2007; Salovey y Mayer, 1990, 1997, citados en Fernández y Extremera, 2005).

Bueno (2017) define las emociones como patrones de comportamiento que de forma automática y preconsciente aparecen en un individuo ante cualquier situación que conlleve un cambio. De hecho, el autor clarifica la diferencia entre sentimientos y emociones, ya que desde el punto de vista de la neurociencia no son lo mismo. La diferencia radica en que los sentimientos suponen la racionalización y la verbalización de las emociones.

En los próximos apartados se tratará de dar respuesta a las preguntas planteadas en la introducción de esta investigación.

\subsection{AA. CC. y talento}

\subsubsection{La atención de los alumnos con AA. CC.}

P1. ¿Necesitan alguna atención especial los alumnos más capaces?

P2. ¿Puede un alumno con AA. CC. fracasar en la escuela?

P3. ¿Qué ocurre con los niños bien dotados que no son atendidos correctamente? 
Ahora se sabe que inteligencia y creatividad están íntimamente relacionadas con las altas capacidades y el talento. Pero durante mucho tiempo se ha interpretado la superdotación a partir del resultado de los test de inteligencia. Aún hoy, existe cierta confusión al respecto y se asocia superdotación únicamente con Cl. Así, un Cl superior a 130, obtenido por la realización de un test de inteligencia, ha venido siendo el indicador de la superdotación en el ámbito escolar, pero en la actualidad se sabe que el Cl por sí solo no determina las AA. CC. (De Mirandés, 2001).

Para Sternberg y O'Hara (2005), algunas personas muy inteligentes, con un Cl superior a 130, pueden no desarrollar todo su potencial creativo, quedando enmascarado por su elevada capacidad intelectual, entendida esta desde el punto de vista analítico. De ahí la importancia de considerar tanto inteligencia como creatividad en la definición de las altas capacidades.

Se tiende a pensar que los alumnos con AA. CC. destacan por sí solos, es decir, que necesariamente han de presentar un alto rendimiento académico y que, por lo tanto, no necesitan ayuda o atención especial. Según De Mirandés (2001), «confundir la capacidad con el rendimiento escolar es el daño más grande que los sistemas educativos están produciendo a estos alumnos» (p. 12).

\section{Confundir la capacidad con el rendimiento escolar es el daño más grande que los sistemas educativos están produciendo a estos alumnos}

Conforme indican Albes et al. (2013), existen una serie de mitos al respecto que están produciendo que los alumnos con AA. CC. no estén siendo atendidos. Esos mitos pasan por pensar que triunfan en todas las áreas, que avanzan sin necesidad de ayuda, que todos necesitan de atención específica o terapéutica, que tienen problemas para relacionarse, que son personas inestables o que no necesitan estimulación.

También se han asociado durante mucho tiempo las AA. CC. al buen rendimiento académico, lo cual no es del todo cierto. Un superdotado puede mostrar o no talento académico. García, Abaurrea e Iriarte (1997) hacen referencia a ello argumentando que los alumnos con talento académico ciertamente muestran unas capacidades relevantes para el aprendizaje, aprenden rápido y son capaces de manejar gran cantidad de información, sin embargo, no son muy creativos y no se sienten cómodos en situaciones menos estructuradas.

García et al. (1997), de hecho, distinguen diferentes tipos de talento. Así, según dichos autores se puede hablar no solo de talento académico, sino también de talento matemático, creativo, social y artístico.

Sin embargo, la realidad es que las evidencias de las AA. CC. se manifiestan de múltiples maneras y, en contra de lo que intuitivamente se pueda pensar, los alumnos con esta potencialidad sí requieren de medidas educativas especiales (Marland, 1971). 
Podría decirse que la principal diferencia entre los niños con AA. CC. y el resto no está en el Cl. No es una diferencia cuantitativa, sino cualitativa, ya que los niños más capaces sienten y piensan de manera diferente a los demás y aprenden siguiendo sus propios estilos de aprendizaje (Martín y Vargas, 2014).

Además, «las neurociencias nos han permitido conocer que tanto el desarrollo morfológico como la configuración final del cerebro en las personas superdotadas y de altas capacidades es muy diferente que en las personas estándar» (Organización Médica Colegial [OMC], Consejo General de Colegios Oficiales de Médicos de España, Consejo Superior de Expertos en Altas Capacidades y Fundación para la Formación de la OMC, 2014, p. 10).

Los alumnos bien dotados se caracterizan por poseer estilos de aprendizaje significativamente diferentes al resto. Así, «los estilos de los alumnos superdotados toman fundamento en el aprendizaje autónomo, la metacognición, la automotivación permanente, en definitiva, la autorregulación del propio proceso de construcción del aprendizaje, orientado a aprender a aprender» (De Mirandés, 2004, p. 9). Por ejemplo, para los alumnos con AA. CC. se hace imprescindible la eliminación total de trabajos repetitivos (De Mirandés, 2004).

La guía de la OMC et al. (2014) añade un aporte más a los estilos de aprendizaje. Así pues, indican los autores que los estilos de aprendizaje, además de ser imprescindibles para los alumnos con AA. CC., suponen un beneficio que enriquece al resto del grupo.

Una vez aclarado que las AA. CC. y el talento académico no tienen por qué coincidir en un mismo individuo, y que los estilos de aprendizaje de los niños más capaces son variados, y pocas veces identificados, no es complicado comprender por qué las cifras de fracaso escolar entre estos alumnos son tan altas en nuestro país. Así, Garrido (2007) indica que el $70 \%$ de los estudiantes bien dotados presenta bajo rendimiento escolar y que el fracaso escolar afecta a entre el 35 y el $50 \%$ de ellos.

Los niños con AA. CC. presentan a menudo una característica que se conoce como «disincronía interna». Esta disincronía interna es consecuencia del proceso de maduración asíncrono que experimentan y que se caracteriza por un desarrollo no homogéneo en las áreas social, cognitiva, psicomotora y afectiva (Albes et al., 2013).

Cuando un alumno con AA. CC. no es atendido correctamente, no se le permite aprender según sus estilos de aprendizaje propios o se le somete a la realización de ejercicios repetitivos, además de aburrimiento, puede llegar a presentar lo que se conoce como «disincronía escolar», la cual potencia la disincronía interna. Adicionalmente, puede presentar un «trastorno de difusión de la identidad». Este síndrome le impide reconocerse como persona superdotada y se ve a sí mismo como un «bicho raro» (De Mirandés, 2004).

Es necesaria pues la formación y el cambio de concepto que los docentes tienen sobre las AA. CC. para evitar que esa disincronía escolar aparezca, llevando a los alumnos más capaces al fracaso escolar. Es importante asimismo que se atiendan las AA. CC., pero es evidente que no se puede atender a los alumnos con AA. CC. si no se detectan previamente. 


\subsubsection{La identificación de los alumnos con AA. CC.}

P4. ¿Qué porcentaje de estudiantes con AA. CC. se detecta y qué porcentaje pasa desapercibido?

P5. ¿Se pueden detectar las AA. CC. en educación secundaria si no se ha hecho antes?

P6. ¿Se pueden perder las AA. CC. si no se identifican y potencian?

Conocer las características reales de los niños con AA. CC. fuera de los prejuicios y mitos extendidos entre la comunidad educativa es de gran ayuda a la hora de identificarlos.

Estos chicos se caracterizan por la "disincronía interna», que ya hemos mencionado con anterioridad; una adquisición precoz del lenguaje y habilidades de razonamiento; conversaciones e intereses propios de niños más mayores; preguntas perspicaces derivadas de su naturaleza curiosa; comprensión de conceptos de manera rápida e intuitiva; una increíble memoria a largo plazo; producción de problemas difícilmente imaginables; facilidad para relacionar ideas o conceptos; sentido del humor inusual para su edad; pensamiento divergente; obtención de placer en la resolución de problemas; talento en una o varias áreas, como la música, las matemáticas, la lectura o el dibujo; alta sensibilidad y necesidad de perfeccionismo; y, por último, como ya dijimos, una gran intensidad a la hora de sentir las emociones (Martín y Vargas, 2014).

Como hemos comentado anteriormente, en la detección de las AA. CC., contrariamente a lo que se suele pensar, lo más importante no es el valor del $\mathrm{Cl}$ obtenido en los test de inteligencia. Un $\mathrm{Cl}$ de 130 no es de por sí determinante en la identificación de la superdotación:

Para identificar con rigor a un alumno superdotado ya no es suficiente el criterio psicométrico y cuantitativo aplicado hasta los años setenta. En la actualidad se ha de complementar, necesariamente, con modelos diversos de diagnóstico en los que se contemplen el mayor número posible de las variables de la excepcionalidad (Martín, 2000, p. 33).
En la detección de las AA. CC., contrariamente a lo que se suele pensar, lo más importante no es el valor del CI obtenido en los test de inteligencia. Un CI de 130 no es de por sí determinante en la identificación de la superdotación

Tourón (2018) añade que un $\mathrm{Cl}$ situado en el percentil 90, es decir, en el $10 \%$ superior, corresponde de hecho a un $\mathrm{Cl}$ de 120. Así, de los 8.000 .000 de alumnos escolarizados en 
España, debería haber, por tanto, alrededor de 800.000 detectados como de AA. CC. Pero solamente están identificados unos 25.000. La cifra dista mucho de la esperada.

Por otra parte, Marland (1971) y Tourón (2006) coinciden en la necesidad de no confundir superdotación con rendimiento. Para Marland, los niños con AA. CC. son niños que tal vez no demuestren su capacidad en términos de rendimiento, pero presentan la potencialidad. De modo que la detección de los niños bien dotados no puede realizarse desde la perspectiva del rendimiento.

En la detección de las AA. CC. por parte de los profesionales de la educación en nuestro país se suele cometer un error, según apuntan los expertos. El error consiste en aplicar el estado final de talento para reconocer el estado inicial de superdotación. Esta teoría sitúa las AA. CC. como la interacción de tres factores: alta inteligencia, alta creatividad y motivación o compromiso con la tarea (De Mirandés, 2001). Así, se aplica equivocadamente un modelo de intervención como si fuera un modelo de detección.

El modelo de los tres anillos de Renzulli sitúa las AA. CC. en la intersección entre las tres capacidades o factores (véase figura 1). Lo que define la capacidad es la interacción entre los tres anillos o factores (García et al., 1997).

Figura 1. Modelo de los tres anillos de Renzulli

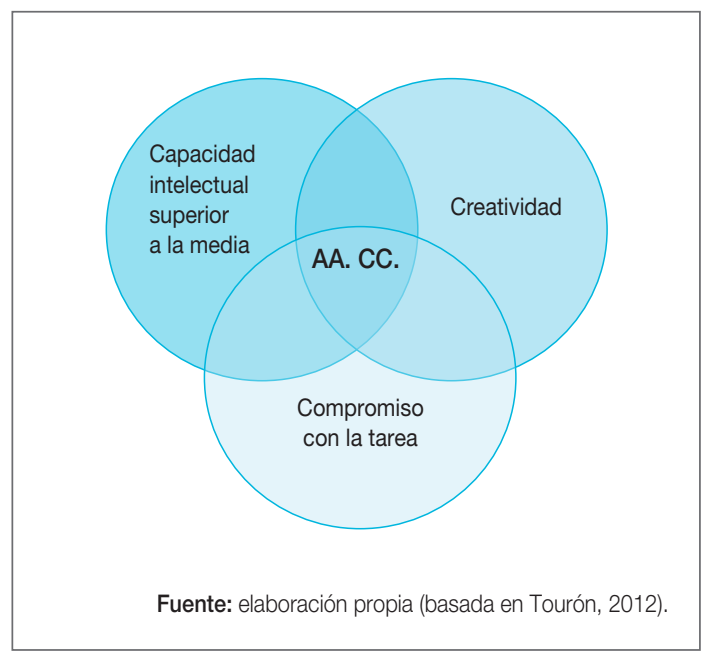

Tourón (2012) indica que el propio Renzulli recuerda que la clave no está en resolver si el alumno es o no de AA. CC., sino en proporcionar oportunidades en las que los estudiantes puedan mostrar el comportamiento superdotado. Y es que el modelo de Renzulli no es un modelo de diagnóstico, sino de intervención. Para que se desarrolle la creatividad, el talento y el alto compromiso con la tarea en una determinada situación habrá que crear las condiciones necesarias.

La plasticidad neural hace del cerebro un órgano en construcción y reconstrucción permanente (Bueno, 2017). Existe una segunda oportunidad durante la adolescencia, ya que el cerebro de los adolescentes se remodela por completo, lo cual es crucial para el aprendizaje (Marina, 2015). 
Los nuevos avances de las neurociencias nos han permitido saber que estos niños nacen con un córtex cerebral más grueso, es decir, con un cerebro morfológicamente distinto, lo cual se traduce en precocidad al hablar, caminar, leer o escribir... Pero es que, además, al llegar a la adolescencia sufren una poda neuronal más intensa, lo que dotará a sus cerebros de una mayor plasticidad y predisposición al aprendizaje (Martín y Vargas, 2014, p. 40).

Esto justifica aún más la necesidad de atender las AA. CC. en la etapa que nos incumbe, la de la educación secundaria obligatoria (ESO). Es más, las capacidades y el talento que no se potencian y desarrollan se acaban por perder (OMC, 2014).

\subsection{Respuestas educativas}

\subsubsection{Respuestas educativas tradicionales para la atención de las AA. CC. Aceleración y enriquecimiento}

P7. ¿Son la aceleración y el enriquecimiento las mejores respuestas educativas para los alumnos con AA. CC.?

P8. ¿Cuáles son las respuestas educativas más adecuadas para atender a este tipo de alumnos?

En algunos centros públicos, la atención a los alumnos con AA. CC. no se realiza porque la identificación es requisito indispensable para que se ponga en marcha alguna medida que los atienda. Para adoptar medidas, como la aceleración, habitualmente los centros educativos requieren una evaluación positiva o dictamen, es decir, un informe, que, en el caso de la Comunidad de Madrid, será realizado por el equipo de Orientación Educativa y Psicopedagógica (para los centros de infantil y primaria) o por el Departamento de Orientación (para los centros de secundaria), en el que se dé un diagnóstico positivo de AA. CC. Sin embargo, tal y como apuntan García et al. (1997):

Desde el punto de vista educativo, más que la identificación estricta de alumnos altamente dotados, interesa la identificación y valoración de sus necesidades educativas, por lo que conviene que las actuaciones a nivel pedagógico tengan mayor preponderancia que el diagnóstico psicológico (p. 14).

De este modo, la atención de los alumnos más capaces está supeditada a la existencia de un informe de diagnóstico. Y como explicamos anteriormente, dadas las malas in- 
terpretaciones que se realizan del modelo de los tres anillos de Renzulli, y remitiéndonos a las cifras de alumnos de AA. CC. identificados en nuestro país, podría pensarse que no se está haciendo todo lo bien que se debería.

Una de las respuestas educativas que tradicionalmente se utiliza con los niños que tienen AA. CC. es la conocida como «aceleración». Habitualmente, se entiende la aceleración como adelantar al alumno de curso. La ley, en concreto el Real Decreto 943/2003, de 18 de julio (Boletín Oficial del Estado [BOE], 2003), permite hasta tres aceleraciones de curso en todo el tiempo de escolarización de un alumno, una por cada ciclo. No obstante, la aceleración sería cualquier medida de flexibilización curricular o compactación curricular que permita al alumno avanzar más rápido por el currículo (Tourón, Peralta y Repáraz, 1996). De modo que las medidas de flexibilización son variadas.

En cuanto a la idoneidad o no de la aceleración de curso, hay diversidad de criterios. Para algunos autores, es una medida poco acertada en numerosos casos, ya que atiende únicamente a diferencias cuantitativas, pero no contempla las diferencias cualitativas, es decir, aquellas que tienen que ver con los diferentes estilos de aprendizaje de los alumnos bien dotados (De Mirandés, 2001).

Sin embargo, Tourón et al. (1996) sí defienden los resultados positivos de la aceleración, ya que de lo contrario los alumnos más capaces viven la escolarización a un ritmo ralentizado que los lleva a no desarrollar hábitos de trabajo adecuados, a no realizar esfuerzo intelectual para progresar en su aprendizaje y a perder interés por la escuela. Si se entiende la aceleración no únicamente como el salto de curso, sino en términos de proponer «respuestas multinivel», como las de Collicot (1991), la aceleración puede ser una medida que efectivamente beneficie a todos.

La segunda medida por excelencia aplicada a la atención de los niños con AA. CC. es el «enriquecimiento», también conocido con los términos «adaptaciones curriculares» o «ampliaciones curriculares».

La crítica más común a esta medida es que al alumno se le suele dar una mayor carga de trabajo, una mayor cantidad de contenidos curriculares, que pueden ser adecuados para aquel con talento académico, pero para nada apropiados en el caso de los alumnos superdotados (De Mirandés, 2001).

El enfoque defendido por la educación inclusiva cambia el foco de la cuestión. Así, si la primera pregunta que aparece es si un alumno es o no superdotado, esta debe relegarse y dar prioridad a la cuestión de si la respuesta educativa planificada para el grupo se ajusta también a las necesidades educativas de los alumnos con AA. CC. (García et al., 1997). Una
Una educación inclusiva que piense en el beneficio y en el desarrollo del máximo potencial de todos los alumnos no debería olvidarse de los más capaces 
educación inclusiva que piense en el beneficio y en el desarrollo del máximo potencial de todos los alumnos no debería olvidarse de los más capaces.

\subsubsection{Otras respuestas educativas para los alumnos con AA. CC.}

P9. ¿Se puede responder a las necesidades educativas de estos alumnos desde la inclusión educativa?

P10. ¿Cómo se motiva a un alumno con AA. CC. para que su aprendizaje sea significativo?

P11. Teniendo en cuenta los aportes de la neurociencia, ¿cómo podemos, a la vez, responder a las necesidades de estos alumnos y avivar en ellos la curiosidad y la motivación por el aprendizaje?

Una de las metodologías utilizadas en el aula que mejor se adapta a los principios de la educación inclusiva es la del «aprendizaje cooperativo». Así, el aprendizaje cooperativo quedaría al servicio de la escuela inclusiva, además de proporcionar grandes oportunidades de aprendizaje a los alumnos con AA. CC. (Torrego, Monge, Pedrajas y Martínez, 2015).

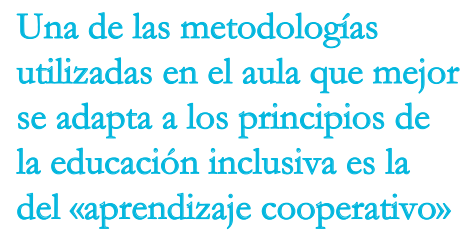

Una de las metodologías utilizadas en el aula que mejor se adapta a los principios de la educación inclusiva es la del «aprendizaje cooperativo»

Para Bueno (2017), «el trabajo cooperativo y colaborativo es una de las estrategias de trabajo que proporciona más placer social y, en consecuencia, que permite alcanzar los aprendizajes de manera más integrada y eficiente» (p. 125). Así pues, despierta en los alumnos el placer social, que es lo que el cerebro interpreta como de máxima utilidad. Los aprendizajes cooperativos y colaborativos, sostiene Bueno (2017), implican la activación de más redes neurales y son más significativos para los alumnos.

Tal vez la mayor discusión al respecto del beneficio que el aprendizaje cooperativo proporciona a los alumnos con AA. CC. se encuentra en el momento de realizar los agrupamientos.

Los partidarios de los agrupamientos heterogéneos argumentan que estos agrupamientos proporcionan a los alumnos una riqueza de aprendizajes, dado que se potencian situaciones de conflicto sociocognitivo y se produce una complementariedad de funciones y destrezas. Además, sostienen la importancia de que los grupos sean pequeños (de 4 a 6 personas) y estables durante algún tiempo (Torrego et al., 2015). 
Por otra parte, algunos autores cuestionan tanto los agrupamientos heterogéneos como los homogéneos. Estos últimos podrían justificarse desde el punto de vista del profesor que encuentra su labor más sencilla cuando se agrupa a los estudiantes en un grupo homogéneo (González, 2002). Sin embargo, ni siquiera juntando a niños de AA. CC. podemos garantizar que el grupo sea homogéneo, ya que, incluso entre el colectivo de los alumnos más capaces, la heterogeneidad está garantizada.

Los «agrupamientos flexibles», sin embargo, buscan que no solo los alumnos con AA. CC., sino también el resto, se puedan agrupar en determinados momentos con compañeros de nivel de competencia similar, o por ciertas áreas de interés, o habilidades específicas, permitiendo incluso que haya alumnos de diferentes edades juntos en el mismo grupo (Blanco, Ríos y Benavides 2004).

Además del aprendizaje cooperativo, existen otras metodologías activas que benefician a todos los alumnos y, por supuesto, también a aquellos con AA. CC. El TBL, como se conoce en inglés, es una estrategia muy interesante para motivar a los estudiantes y lograr un aprendizaje significativo (Costa y Swartz, 2008).
El TBL es una estrategia muy interesante para motivar a los estudiantes y lograr un aprendizaje significativo

Swartz, Costa, Beyer, Reagan y Kallick (2007) describen el TBL como un conjunto de estrategias mediante las cuales las habilidades de pensamiento y los hábitos mentales importantes se hacen explícitos. Gracias a ellas, los estudiantes piensan activamente sobre los elementos importantes del currículo, o del contenido tratado, a la vez que consiguen crear una capa de metacognición sobre lo aprendido. El TBL desarrolla el pensamiento hábil y los hábitos mentales apropiados que dirigen el pensamiento hacia estados avanzados. Esta metodología se plantea pues como un proceso de filtrado o refinamiento y adaptación de técnicas docentes para enseñar a los estudiantes de tal manera que mejoren la calidad de su pensamiento, todo ello de forma integrada en la instrucción habitual del contenido establecido. Esta práctica, aseguran los autores, mejora dramáticamente la comprensión y el aprendizaje.

Para aplicar el TBL en el aula, es importante el uso regular de diferentes rutinas de pensamiento, las cuales enriquecen el proceso y benefician a todo el alumnado. Con estas rutinas de pensamiento se trabajan destrezas que implican procesos cognitivos de orden superior, lo cual se complementa con la jerarquía de destrezas presente en la taxonomía de Bloom (Bloom, Engelhart, Furst, Hill y Krathwohl, 1956). Los organizadores gráficos son de gran ayuda para ponerlas en práctica.

Además, el TBL hace especial incidencia en la búsqueda y en el procesado de información relevante, para lo cual se pueden usar los mencionados organizadores gráficos, 
así como en la recopilación de la información obtenida y en la comprobación de su corrección (Swartz et al., 2007).

Por otra parte, el aprendizaje basado en proyectos (ABP) y los aprendizajes transversales, que evitan la estanqueidad del conocimiento en asignaturas concretas, son más apropiados en el proceso educativo, puesto que el cerebro funciona como un todo integrado (Bueno, 2017).

Puede decirse que el ABP nació hace cien años. Kilpatrick (1918), discípulo del psicólogo, pedagogo y filósofo John Dewey, publicó un ensayo titulado «El método de proyectos» en el que define el ABP como un acto lleno de propósito. El ABP deja libertad de acción al alumno, lo cual mejora la motivación de este.

Para Vergara (2015), el ABP es un marco que permite establecer el proceso de enseñanza-aprendizaje desde otra óptica. Vizcaíno (2016) añade que trabajar por proyectos es una estrategia que parte de la escucha. Es importante identificar qué le interesa al aprendiz, qué acontecimientos están marcando su vida y cómo conecta todo eso con los contenidos que el docente desea trabajar en el aula.

Desde el ABP se puede despertar la motivación de los alumnos. Para la neurociencia (Bueno, 2017), la motivación es una reacción mental vigorizante que facilita mantener la atención. Está relacionada con el optimismo y es el detonante del «aprender a aprender», una de las competencias clave recogidas en el Real Decreto 126/2014, de 28 de febrero (BOE, 2014a). El ABP también permite la introducción de sorpresas inesperadas, las cuales, según Bueno (2017), «captan la atención mediante un mecanismo automático del cerebro que permite centrar los pensamientos y las respuestas en el problema planteado» (p. 175).

Para Mora (2014), si se consigue despertar la curiosidad de todos los alumnos, produciendo además emociones positivas en ellos, el aprendizaje está garantizado. El autor plantea la hipotética situación de que una jirafa impartiera un día una clase. En dicho contexto, los alumnos tendrían sus amígdalas encendidas y los aprendizajes provocados por la jirafa serían duraderos.

Los aprendizajes que ponen en juego componentes emocionales son interpretados por el cerebro como claves para la supervivencia y, por tanto, se almacenan mejor y permanecen por más tiempo (Bueno, 2017).

\subsection{La instrucción multinivel}

Una manera de permitir la aceleración sin realizar el salto de curso, lo cual puede ser una medida controvertida, es la propuesta de currículo multinivel de Collicot (1991), que se fundamenta, a su vez, en la taxonomía propuesta por Bloom et al. (1956). 
Bloom y sus colaboradores publicaron en 1956 una taxonomía que era un intento de clasificación de las metas de aprendizaje fijadas por los docentes (Tourón, 2016). Esta metodología trata de explicar cómo se produce el aprendizaje, y su aplicación a la programación del aula permite un aprendizaje significativo.

La taxonomía de Bloom ha sido revisada y, según dicha revisión (Churches, 2001), se presenta en seis diferentes niveles, como se pueden ver en el cuadro 1.

Los seis niveles que se acaban de mencionar abarcan desde procesos cognitivos de nivel inferior de complejidad hasta procesos cognitivos de mayor nivel de abstracción:

\section{La taxonomía de Bloom ha sido revisada y se presenta en seis diferentes niveles que abarcan desde procesos cognitivos de nivel inferior de complejidad hasta procesos cognitivos de mayor nivel de abstracción}

- Nivel 1 (recordar). En este estadio se trata de que el alumno recuerde conocimientos que ya posee. Los verbos clave son «identificar», «nombrar», «localizar», «describir», etc.

- Nivel 2 (comprender). En este nivel se construye significado y se relacionan conceptos entre sí. Los verbos clave son «interpretar», «resumir», "parafrasear», «clasificar», «comparar», «explicar» y «ejemplificar».

- Nivel 3 (aplicar). Se trata de llevar a cabo un procedimiento mediante su ejecución. El alumno toma un rol activo y debe poner en práctica el conocimiento adquirido. Los verbos clave son «implementar», «ejecutar»y «usar».

- Nivel 4 (analizar). En este nivel se trata de disgregar conceptos, determinando las partes relacionadas entre sí o dentro de un conjunto o grupo mayor. Se procede partiendo de lo global para llegar a lo específico. Es importante que el alumno encuentre la jerarquía subyacente a las ideas, expresando la relación entre las mismas. Los verbos clave son «comparar», "organizar», «deconstruir» $\mathrm{y}$ «atribuir».

- Nivel 5 (evaluar). El estudiante realiza, a través de la comprobación y la crítica, diferentes juicios de valor. Se pone el foco en el proceso, los materiales, los métodos o los contenidos. Los verbos clave son «comprobar», «realizar hipótesis», «criticar», «experimentar», «juzgar», «testear»y «detectar».

- Nivel 6 (crear). Por último, el nivel superior supone unir los elementos para crear un producto que sea un todo coherente. Se pueden reorganizar los elementos en una nueva estructura hasta que el alumno sea capaz de crear su propio conocimiento mediante la planificación o producción. Los verbos clave son «diseñar», «construir», «planificar», «producir», «inventar»y «hacer». 


\section{Cuadro 1. Taxonomía de Bloom}

\begin{tabular}{|c|c|c|c|c|c|}
\hline & & \multicolumn{4}{|c|}{ La dimensión del conocimiento } \\
\hline & & $\begin{array}{l}\text { Factual } \\
\text { Los elementos bási- } \\
\text { cos que un estudian- } \\
\text { te debe conocer para } \\
\text { estar familiarizado } \\
\text { con una disciplina o } \\
\text { para resolver proble- } \\
\text { mas sobre ella. }\end{array}$ & \begin{tabular}{l}
\multicolumn{1}{c}{ Conceptual } \\
Las interrelaciones \\
entre los elementos \\
básicos, dentro de \\
una estructura más \\
amplia, que permiten \\
un funcionamiento \\
conjunto.
\end{tabular} & $\begin{array}{l}\text { Procedimental } \\
\text { Cómo hacer algo, } \\
\text { métodos de investi- } \\
\text { gación, criterios para } \\
\text { utilizar las propias } \\
\text { destrezas, algorítmos, } \\
\text { técnicas y métodos. }\end{array}$ & $\begin{array}{l}\text { Metacognitivo } \\
\text { Conocimiento de la } \\
\text { cognición en general, } \\
\text { así como consciencia } \\
\text { y conocimiento sobre } \\
\text { la propia cognición. }\end{array}$ \\
\hline \multirow{6}{*}{$\begin{array}{l}\text { La dimensión } \\
\text { del proceso } \\
\text { cognitivo }\end{array}$} & $\begin{array}{l}\text { Crear } \\
\text { Juntar un número de } \\
\text { elementos para formar } \\
\text { un todo coherente o } \\
\text { funcional; reorganizar } \\
\text { los elementos dentro } \\
\text { de un nuevo patrón o } \\
\text { estructura. }\end{array}$ & $\begin{array}{l}\text { Generar } \\
\text { un registro de las ac- } \\
\text { tividades diarias. }\end{array}$ & $\begin{array}{c}\text { Establecer } \\
\text { un grupo de expertos. }\end{array}$ & $\begin{array}{l}\quad \text { Diseñar } \\
\text { un diagrama de flujo } \\
\text { eficiente para un pro- } \\
\text { yecto. }\end{array}$ & $\begin{array}{l}\text { Crear } \\
\text { un portafolio de apren- } \\
\text { dizajes. }\end{array}$ \\
\hline & $\begin{array}{l}\text { Evaluar } \\
\text { Realizar juicios basa- } \\
\text { dos en criterios o es- } \\
\text { tándares. }\end{array}$ & $\begin{array}{l}\text { Comprobar } \\
\text { la consistencia entre } \\
\text { diversas fuentes. }\end{array}$ & $\begin{array}{l}\text { Determinar } \\
\text { la relevancia de los re- } \\
\text { sultados. }\end{array}$ & $\begin{array}{l}\quad \text { Juzgar } \\
\text { la eficiencia de los pro- } \\
\text { cedimientos de mues- } \\
\text { treo. }\end{array}$ & $\begin{array}{l}\text { Reflexionar } \\
\text { sobre el propio pro- } \\
\text { greso. }\end{array}$ \\
\hline & $\begin{array}{l}\text { Analizar } \\
\text { Descomponer el ma- } \\
\text { terial en sus partes } \\
\text { constitutivas y deter- } \\
\text { minar cómo se rela- } \\
\text { cionan unas partes } \\
\text { con otras, así como } \\
\text { con una estructura } \\
\text { general o propósito. }\end{array}$ & \begin{tabular}{l}
\multicolumn{1}{c}{ Seleccionar } \\
la lista de actividades \\
más completa.
\end{tabular} & $\begin{array}{c}\text { Diferenciar } \\
\text { la cultura alta y baja. }\end{array}$ & $\begin{array}{l}\quad \text { Integrar } \\
\text { la conformidad con las } \\
\text { regulaciones. }\end{array}$ & $\begin{array}{c}\text { Deconstruir } \\
\text { los propios sesgos. }\end{array}$ \\
\hline & $\begin{array}{l}\text { Aplicar } \\
\text { Llevar a cabo un pro- } \\
\text { cedimiento en una si- } \\
\text { tuación dada. }\end{array}$ & $\begin{array}{l}\text { Responder } \\
\text { a preguntas frecuen- } \\
\text { tes sobre algo. }\end{array}$ & $\begin{array}{c}\text { Ofrecer } \\
\text { consejo a los novatos. }\end{array}$ & $\begin{array}{l}\text { Realizar } \\
\text { un test de pH en mues- } \\
\text { tras de agua. }\end{array}$ & $\begin{array}{c}\text { Utilizar } \\
\text { técnicas adecuadas } \\
\text { a nuestras fortalezas. }\end{array}$ \\
\hline & $\begin{array}{l}\text { Comprender } \\
\text { Construir el signifi- } \\
\text { cado a partir de los } \\
\text { mensajes de la ins- } \\
\text { trucción, incluyendo } \\
\text { la comunicación oral, } \\
\text { escrita y gráfica. }\end{array}$ & \begin{tabular}{l}
\multicolumn{1}{c}{ Resumir } \\
características de un \\
nuevo producto.
\end{tabular} & $\begin{array}{l}\quad \text { Clasificar } \\
\text { adhesivos por su to- } \\
\text { xicidad. }\end{array}$ & $\begin{array}{l}\quad \text { Aclarar } \\
\text { instrucciones de mon- } \\
\text { taje. }\end{array}$ & \begin{tabular}{l}
\multicolumn{1}{c}{ Predecir } \\
la propia respuesta al \\
shock cultural.
\end{tabular} \\
\hline & $\begin{array}{l}\text { Recordar } \\
\text { Recuperar de la me- } \\
\text { moria a largo plazo } \\
\text { conocimientos rele- } \\
\text { vantes. }\end{array}$ & $\begin{array}{l}\text { Listar } \\
\text { los colores primarios } \\
\text { y secundarios. }\end{array}$ & $\begin{array}{l}\text { Reconocer } \\
\text { los síntomas del ago- } \\
\text { tamiento. }\end{array}$ & $\begin{array}{l}\text { Recordar } \\
\text { cómo llevar a cabo una } \\
\text { CPR (reanimación car- } \\
\text { diopulmonar). }\end{array}$ & $\begin{array}{l}\text { Identificar } \\
\text { estrategias para rete- } \\
\text { ner información. }\end{array}$ \\
\hline
\end{tabular}

Fuente: Tourón (2017).

Para Bueno (2017), «un niño o adolescente estimulado que pueda decidir, examinar, evaluar, relacionar, memorizar, buscar novedades, etc., y que sienta la necesidad moti- 
vadora de hacerlo, establecerá ya de inicio un mejor sustrato neuronal para ir fijando los nuevos aprendizajes» (p. 174).

La estrategia multinivel permite a los alumnos avanzar a velocidades diferentes por el currículo. Todos los alumnos pasan por los distintos niveles, pero con diferente grado de profundización o complejidad. Este principio es el que se ha llevado a la práctica en la intervención en el aula que se ha diseñado, la cual se detalla en la segunda parte de este documento (véase apartado 3), y a la que nos referiremos como guía multinivel enriquecida.

\section{Segunda parte. Aplicación práctica}

\subsection{Formación previa al diseño de la intervención. Metodología EBI. Requisitos de partida}

La propuesta de intervención que aquí se plantea parte en un inicio de la instrucción multinivel propuesta por Collicot (1991). Para diseñar la guía multinivel enriquecida, ha sido de gran relevancia la formación recibida en dos cursos diferentes realizados en fechas casi simultáneas, previos al diseño de esta investigación.

Uno de los cursos, organizado por la Fundación Escuela Ideo, fue impartido por Paulina Bánfalvi, creadora del blog AA. CC. La Rebelión del Talento y formadora en AA. CC. El curso se titulaba «Altas Capacidades y Desarrollo del Talento» y en él se abordaron los aspectos que ya se han tratado en el marco teórico de este documento, entre otras cosas.

El segundo curso, titulado «Sistema Pedagógico EBI (Educación Básica Interactiva). Formación Inicial al Profesorado» (Fundación Iruaritz-Lezama, 2018b), fue impartido por el personal del departamento de innovación del colegio concertado Santa María la Blanca, con Arantxa Garay-Gordovil al frente, y organizado por la Fundación Iruaritz-Lezama. Este centro inclusivo utiliza la instrucción multinivel para atender a la diversidad, además de fomentar el aprendizaje autónomo y las relaciones significativas entre docentes y estudiantes. El resultado final del trabajo propio de este curso se presentó en formato de porfolio digital (Bailén, 2018b).

En el momento de recibir la formación, el sistema pedagógico EBI se encontraba en una fase de transición. Así, en breve, incluirá nuevas metodologías, como es el TBL, el cual se ha incorporado en esta propuesta de intervención en el aula. 
Si bien el sistema EBI no está específicamente diseñado para estudiantes con AA. CC., sí que parte de una metodología inclusiva multinivel que con ciertas adaptaciones ha servido para el propósito de esta investigación. De hecho, el desarrollo de los talentos de los estudiantes ya está contemplado en las bases pedagógicas del sistema EBI, tal y como se puede leer en la página web del proyecto EBI (Fundación Iruaritz-Lezama, 2018a):

Nuestro compromiso con la atención a la diversidad, la inclusión, la búsqueda de la excelencia y la potenciación de talentos personales encuentra en la incorporación de la tecnología a las aulas una oportunidad para personalizar los procesos de enseñanza-aprendizaje que presentamos a los centros como Lezama Method en el marco del Proyecto EBI.

Los principios del sistema pedagógico EBI son la planificación centrada en el alumno, la construcción de la identidad docente, la construcción de una comunidad de aprendizaje y el currículo basado en la comprensión. Con esta metodología se trabajan diferentes competencias, como la competencia para el aprendizaje autónomo, la competencia comunicativa, la competencia digital y la competencia social y personal. Los fundamentos principales de la metodología son el socioconstructivismo, la enseñanza para la comprensión y el modelo de escuelas inclusivas.

Con todo esto, la propuesta de intervención en el aula aquí diseñada trata de integrar en una sola solución tanto las respuestas educativas tradicionales (aceleración y enriquecimiento) como buena parte del resto de soluciones (currículo multinivel, aprendizaje cooperativo, agrupamientos flexibles y TBL). La propuesta es realista y aplicable, puesto que parte de la metodología EBI que lleva aplicándose en el colegio Santa María la Blanca varios años con excelentes resultados, aunque hasta la fecha sin reparar todavía en el posible beneficio producido en los niños con AA. CC.

\author{
La propuesta de intervención \\ en el aula aquí diseñada trata de \\ integrar en una sola solución \\ tanto las respuestas educativas \\ tradicionales (aceleración y \\ enriquecimiento) como buena parte \\ del resto de soluciones (currículo \\ multinivel, aprendizaje cooperativo, \\ agrupamientos flexibles y 'TBL)
}

Además de incluir el mayor número de respuestas educativas de las tratadas en la primera parte de este documento (véase apartado 2), la intervención en el aula debía tener en cuenta otra serie de cuestiones. El centro y el grupo escogido para aplicar la intervención debía cumplir una serie de requisitos:

- Tener identificados a alumnos con AA. CC. Por supuesto, si no tuviera identificados a los alumnos más capaces, no tendría sentido plantear la intervención aquí diseñada, ya que no podríamos valorar el impacto en los alumnos objeto de nuestro estudio. 
- Ser un centro inclusivo. Una de las ventajas de la guía multinivel es que es de por sí una estrategia de atención a la diversidad, por lo que para valorar no solo el resultado en los alumnos con AA. CC., sino también en alumnos con otras necesidades educativas, es importante que aquellos que precisen de apoyo educativo no salgan del aula.

- Usar metodologías activas. Uno de los grandes retos de esta propuesta es potenciar el trabajo autónomo de los alumnos. Para ello el centro seleccionado debía usar metodologías gracias a las cuales los alumnos contaran con un cierto grado de autonomía que les permitiera trabajar de manera activa.

- El centro no debía estar aplicando ya medidas como la aceleración, la flexibilización de contenidos o el TBL. La intervención en el aula debía suponer una introducción novedosa de respuestas educativas enfocadas a alumnos con AA. CC.

- Uso de las tecnologías de la información y la comunicación (TIC). El centro y los alumnos debían estar habituados a usar ordenadores portátiles, tabletas u otros dispositivos con acceso a internet en el aula y a hacer un uso responsable de todo ello.

\subsection{Diseño de la propuesta de intervención. Elaboración de la guía multinivel enriquecida}

El centro educativo en el que se ha realizado esta intervención es la Escuela Ideo, ubicada en Madrid, en la autovía M-616, que enlaza la ciudad de Alcobendas con la autovía M-607. Este centro cumple con los requisitos de partida mencionados en el apartado anterior.

Para llevar a la práctica esta intervención, se han escogido unos contenidos de $4 .^{\circ}$ de ESO, ubicados en el bloque 4 del currículo (BOE, 2014b), y a un grupo heterogéneo de estudiantes de dicho nivel educativo en el que hay detectados tres alumnos con AA. CC. El contenido elegido ha sido el de funciones y gráficas correspondiente a la asignatura Matemáticas Orientadas a las Enseñanzas Académicas. No obstante, la docente que imparte las clases de matemáticas a este grupo, Raquel Hernández Nevado, decidió, tras conocer la propuesta de intervención, que la usaría con un grupo más en el que hay identificados dos alumnos con AA. CC.

El diseño del instrumento de intervención, es decir, la guía multinivel enriquecida, ha sido supervisado por dos de las personas a cargo del departamento de innovación del colegio Santa María la Blanca, en el que se usa la metodología EBI. Uno de los elementos centrales de dicha metodología, de la que ya se ha hablado anteriormente, son las llamadas «guías de aprendizaje». Inicialmente, eran unos documentos elaborados por los profesores especialistas de cada materia con los que facilitaban el proceso de aprendizaje de los estudiantes, la atención a la diversidad y la planificación docente. 
Así, la programación de una asignatura está formada por el conjunto completo de «guías de aprendizaje». Sin embargo, la propuesta que se hace en esta intervención no se limita a un único documento, sino que se ha elaborado una guía enriquecida en formato porfolio digital o blog, usando la herramienta Google Sites (Bailén, 2018a). Este es de hecho el formato de guía al que está migrando la metodología EBI.

De este modo, la guía de aprendizaje cumple dos funciones:

- Es una herramienta de programación de aula para el profesor especialista.

- Es una herramienta que facilita el aprendizaje autónomo del alumno en el aula.

Como se puede ver en el cuadro 2, las guías de aprendizaje se estructuran en cinco partes que se corresponden con los niveles de la taxonomía de Bloom de la siguiente manera:

Cuadro 2. Relación entre la taxonomía de Bloom y las partes de la guía

\begin{tabular}{l|ll}
\multicolumn{1}{c|}{ Taxonomía de Bloom } & \multicolumn{1}{c}{ Parte de la guía } & Objetivos \\
\hline Recordar & Activa. & Activar y emocionar. \\
\hline Comprender & Investiga. & Organizar y recolectar. \\
\hline Aplicar y analizar & Desarrolla y reflexiona. & Poner en práctica. \\
\hline Crear & Relaciona. & Conectar y transferir. \\
\hline Evaluar & Evalúa. & Evidenciar y valorar. \\
\hline
\end{tabular}

En la elaboración de esta propuesta de intervención en el aula, en formato de guía enriquecida, se ha usado una recopilación de rutinas de pensamiento y sus organizadores gráficos, siguiendo el planteamiento TBL de Costa y Swartz (2008), de entre las cuales se han escogido las que mejor se adaptaban al propósito de esta propuesta. También se ha tratado de enriquecer la guía teniendo en cuenta los diferentes estilos de aprendizaje, estilos cognitivos o inteligencias múltiples, y se han planteado diversas actividades cooperativas (véase figura 2). 
Figura 2. Elaboración de una guía de aprendizaje

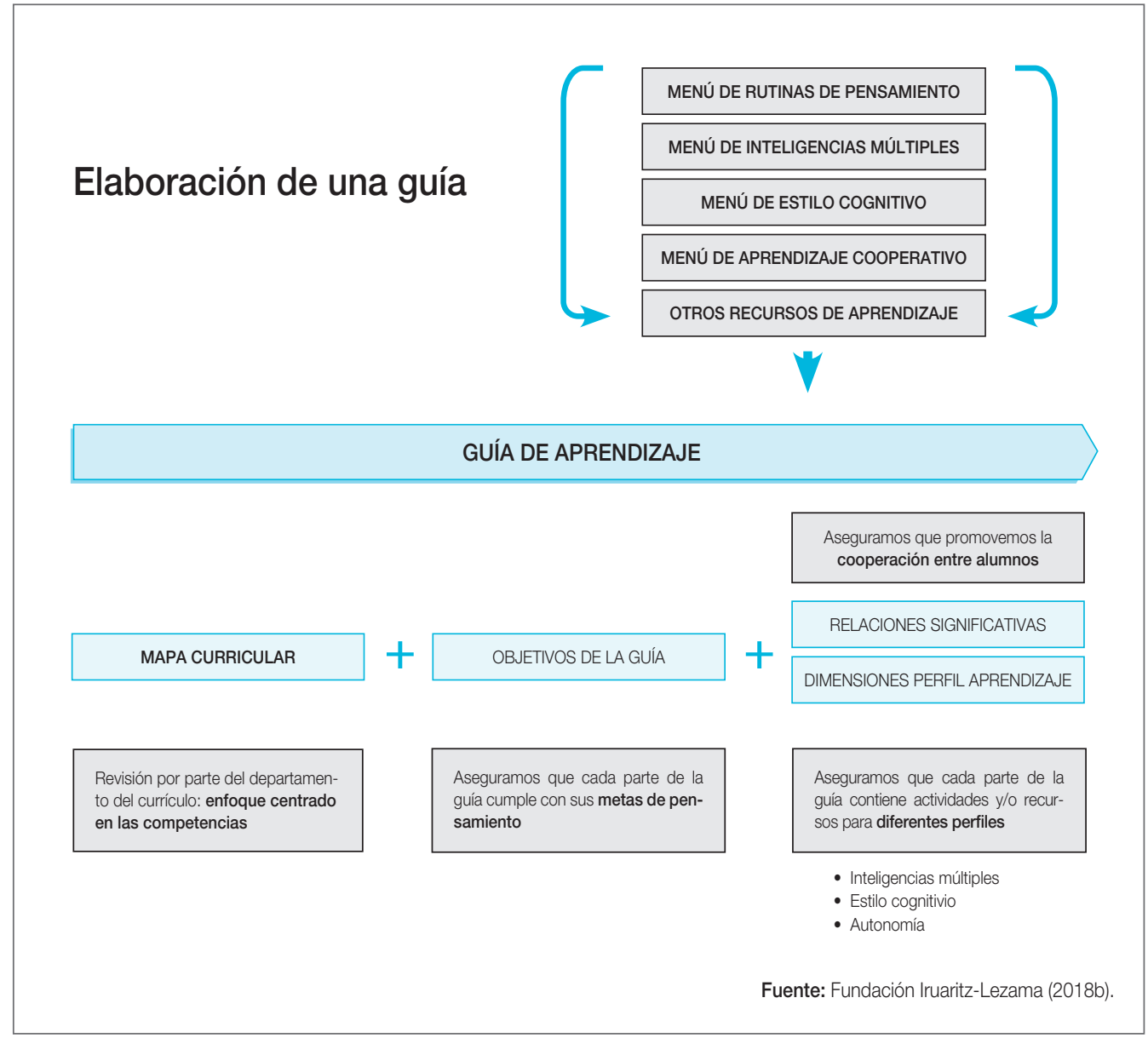

La guía sobre funciones y gráficas para $4 .^{\circ}$ de ESO diseñada para esta propuesta de intervención, y con la que se ha trabajado en el aula, está disponible para su consulta en internet (Bailén, 2018a) ${ }^{1}$. Consta de las cinco partes anteriormente indicadas en las que se distribuyen contenidos y actividades de la manera que veremos a continuación.

Además, tal y como se recoge en la hoja de cálculo disponible en la portada de la guía (Bailén, 2018a), las actividades se distribuyen en dos itinerarios diferentes, siendo el itine-

1 Se puede visitar en <https://sites.google.com/view/4-eso-funciones/funciones-y-graficas>. 
rario 2 el que se ha usado con los alumnos de AA. CC. y con niveles de competencia matemática más elevados. Se ha informado a los alumnos de esta distinción en itinerarios, pero no del propósito de los mismos.

La primera parte de la guía, denominada "Activa», trata de que los alumnos recuperen conocimientos previos y asocien el aprendizaje a emociones positivas. Para esta parte se han planteado tres actividades únicamente, siendo una de ellas la rutina de pensamiento Chalk Talk (véase cuadro 3).

Cuadro 3. Relación de actividades de "Activa»

\begin{tabular}{c|c|c|l|l|c|c}
$\begin{array}{c}\text { Parte de } \\
\text { la guía }\end{array}$ & Actividad & $\begin{array}{l}\text { Tipo de actividad/ } \\
\text { metodología }\end{array}$ & Desarrollo & $\begin{array}{c}\text { Objetivo de } \\
\text { la actividad }\end{array}$ & $\begin{array}{c}\text { Tiempo } \\
\text { Sesión }\end{array}$ \\
Activa & A1 & $\begin{array}{l}\text { Cooperativa y } \\
\text { ludificada. }\end{array}$ & $\begin{array}{l}\text { Juego } \\
\text { barquitos. }\end{array}$ & $\begin{array}{l}\text { Despertar el interés del } \\
\text { alumno (emocionar). }\end{array}$ & 1 & 10 \\
Activa & A2 & Cooperativa. & $\begin{array}{l}\text { Gráfica de post } \\
\text { Instagram/hora } \\
\text { del día. }\end{array}$ & $\begin{array}{l}\text { Recuperar } \\
\text { conocimientos previos. }\end{array}$ & 1 & 15 \\
Activa & A3 & $\begin{array}{l}\text { Rutina de } \\
\text { pensamiento } \\
\text { Chalk Talk. }\end{array}$ & $\begin{array}{l}\text { Rutina de } \\
\text { pensamiento } \\
\text { individual. }\end{array}$ & $\begin{array}{l}\text { Conectar ideas } \\
\text { propias con las de } \\
\text { otros compañeros. }\end{array}$ & 1 & 15 \\
\hline
\end{tabular}

Fuente: elaboración propia.

Los contenidos propiamente dichos están ubicados en la parte denominada «Investiga», cuyo objetivo es que el alumno comprenda y organice lo que aprende (véase cuadro 4).

Para ello, se ha distribuido el contenido en dos bloques: un primer bloque correspondiente al estudio de funciones (características, formas de presentar una función, continuidad, crecimiento y decrecimiento, máximos y mínimos y tasa de variación media) y un segundo bloque en el que se abordan algunas funciones básicas, como son las funciones lineales, cuadráticas y definidas a trozos.

Otras funciones más complejas, como las exponenciales o logarítmicas, no se han llegado a abordar por no disponer de más tiempo.

Esta parte de la guía, además, incluye 18 actividades, de las cuales dos son rutinas de pensamiento. 


\section{Cuadro 4. Relación de actividades de «Investiga»}

\begin{tabular}{|c|c|c|c|c|c|c|}
\hline $\begin{array}{l}\text { Parte de } \\
\text { la guía }\end{array}$ & Actividad & $\begin{array}{l}\text { Tipo de actividad/ } \\
\text { metodología }\end{array}$ & Desarrollo & $\begin{array}{l}\text { Objetivo de } \\
\text { la actividad }\end{array}$ & Sesión & $\begin{array}{c}\text { Tiempo } \\
\text { estimado (min) }\end{array}$ \\
\hline Investiga & 11 & $\begin{array}{l}\text { Rutina de } \\
\text { pensamiento } \\
\text { Solía pensar/ } \\
\text { Ahora pienso. }\end{array}$ & $\begin{array}{l}\text { Rutina de } \\
\text { pensamiento } \\
\text { individual. }\end{array}$ & $\begin{array}{l}\text { Comparar el aprendizaje } \\
\text { antes y después de } \\
\text { completar la parte de } \\
\text { «Activa». }\end{array}$ & 2 & 10 \\
\hline Investiga & 12 & Magistral. & $\begin{array}{l}\text { Se explica para } \\
\text { toda la clase. }\end{array}$ & Definir qué es una función. & 2 & 20 \\
\hline Investiga & 13 & Individual. & $\begin{array}{l}\text { Pensar tablas de } \\
\text { valores, gráficas } \\
\text { y funciones. }\end{array}$ & $\begin{array}{l}\text { Unificar en una misma } \\
\text { tarea las tres formas de } \\
\text { presentar una función. }\end{array}$ & 2 & 10 \\
\hline Investiga & 14 & $\begin{array}{l}\text { Cooperativa: } \\
\text { absurdos. }\end{array}$ & $\begin{array}{l}\text { Jugar con los } \\
\text { dominios y los rangos } \\
\text { Geogebra. }\end{array}$ & $\begin{array}{l}\text { Descubrir cómo varía la } \\
\text { gráfica de una función al } \\
\text { variar su fórmula. }\end{array}$ & 3 & 10 \\
\hline Investiga & 15 & $\begin{array}{l}\text { Rutina de } \\
\text { pensamiento } \\
\text { Think/Puzzle/ } \\
\text { Explore. }\end{array}$ & $\begin{array}{l}\text { Rutina de } \\
\text { pensamiento } \\
\text { individual. }\end{array}$ & Explorar funciones nuevas. & 3 & 5 \\
\hline Investiga & 16 & $\begin{array}{l}\text { Individual: mapa } \\
\text { conceptual. }\end{array}$ & $\begin{array}{l}\text { Mapa conceptual } \\
\text { Cmap Cloud de } \\
\text { estudio de funciones. }\end{array}$ & $\begin{array}{l}\text { Organizar lo que ya se } \\
\text { sabe de manera global. }\end{array}$ & 3 & 10 \\
\hline Investiga & 17 & $\begin{array}{l}\text { Individual: } \\
\text { estudiar } \\
\text { crecimiento y } \\
\text { decrecimiento. }\end{array}$ & $\begin{array}{l}\text { Dadas las gráficas, } \\
\text { estudiar crecimiento } \\
\text { y decrecimiento. }\end{array}$ & $\begin{array}{l}\text { Reconocer cuándo una } \\
\text { función crece o decrece. }\end{array}$ & 3 & 5 \\
\hline Investiga & 18 & $\begin{array}{l}\text { Cooperativa: } \\
\text { hipótesis. }\end{array}$ & $\begin{array}{l}\text { Estudio de máximos } \\
\text { y mínimos con } \\
\text { Geogebra. }\end{array}$ & $\begin{array}{l}\text { Comprender qué es un } \\
\text { máximo y un mínimo. }\end{array}$ & 3 & 5 \\
\hline Investiga & 19 & Individual & $\begin{array}{l}\text { Estudio de una } \\
\text { función a partir } \\
\text { de su gráfica. }\end{array}$ & $\begin{array}{l}\text { Comprender cómo se } \\
\text { hace el estudio de una } \\
\text { función. }\end{array}$ & 3 & 5 \\
\hline Investiga & 110 & Individual & $\begin{array}{l}\text { Completar una tabla } \\
\text { para el estudio de } \\
\text { funciones. }\end{array}$ & $\begin{array}{l}\text { Organizar lo que ya } \\
\text { se sabe de manera } \\
\text { secuencial. }\end{array}$ & 4 & 10 \\
\hline
\end{tabular}




\begin{tabular}{|c|c|c|c|c|c|c|}
\hline $\begin{array}{l}\text { Parte de } \\
\text { la guía }\end{array}$ & Actividad & $\begin{array}{l}\text { Tipo de actividad/ } \\
\text { metodología }\end{array}$ & Desarrollo & $\begin{array}{l}\text { Objetivo de } \\
\text { la actividad }\end{array}$ & Sesión & $\begin{array}{c}\text { Tiempo } \\
\text { estimado (min) }\end{array}$ \\
\hline \multicolumn{7}{|l|}{$\triangleright$} \\
\hline Investiga & 111 & Individual & $\begin{array}{l}\text { Aplicación del } \\
\text { concepto de tasa de } \\
\text { variación media. }\end{array}$ & $\begin{array}{l}\text { Entender cómo se calcula } \\
\text { la tasa de variación media. }\end{array}$ & 4 & 5 \\
\hline Investiga & 112 & Individual & $\begin{array}{l}\text { Aplicación del } \\
\text { concepto de tasa } \\
\text { de variación media y } \\
\text { velocidad media. }\end{array}$ & $\begin{array}{l}\text { Entender cómo se calcula } \\
\text { la tasa de variación media } \\
\text { y la velocidad media. }\end{array}$ & 4 & 5 \\
\hline Investiga & 113 & $\begin{array}{l}\text { Cooperativa: } \\
\text { hipótesis. }\end{array}$ & $\begin{array}{l}\text { Estudio de una } \\
\text { función lineal con } \\
\text { Geogebra. }\end{array}$ & $\begin{array}{l}\text { Entender cómo varía la } \\
\text { gráfica de una función lineal } \\
\text { al modificar su fórmula }\end{array}$ & 4 & 10 \\
\hline Investiga & 114 & $\begin{array}{l}\text { Cooperativa: } \\
\text { hipótesis }\end{array}$ & $\begin{array}{l}\text { Estudio de una } \\
\text { función cuadrática } \\
\text { con Geogebra. }\end{array}$ & $\begin{array}{l}\text { Entender cómo varía la } \\
\text { gráfica de una función } \\
\text { cuadrática al modificar } \\
\text { su fórmula. }\end{array}$ & 4 & 10 \\
\hline Investiga & 115 & $\begin{array}{l}\text { Cooperativa: } \\
\text { hipótesis }\end{array}$ & $\begin{array}{l}\text { Estudio de una } \\
\text { función definida a } \\
\text { trozos con Geogebra. }\end{array}$ & $\begin{array}{l}\text { Comprender cómo son } \\
\text { las funciones definidas } \\
\text { a trozos. }\end{array}$ & 5 & 10 \\
\hline Investiga & 116 & $\begin{array}{l}\text { Rutina de } \\
\text { pensamiento Solía } \\
\text { Pensar/Ahora } \\
\text { Pienso }\end{array}$ & $\begin{array}{l}\text { Acabar la segunda } \\
\text { parte de la rutina de } \\
\text { pensamiento. }\end{array}$ & $\begin{array}{l}\text { Comparar el aprendizaje } \\
\text { antes y después de } \\
\text { completar la parte de } \\
\text { "Activa". }\end{array}$ & 5 & 5 \\
\hline Investiga & 117 & Individual & $\begin{array}{l}\text { Realizar el estudio } \\
\text { de una función de } \\
\text { manera no pautada. }\end{array}$ & $\begin{array}{l}\text { Relacionar, mediante la } \\
\text { aplicación de una actividad } \\
\text { anterior, los conceptos } \\
\text { aprendidos. }\end{array}$ & 5 & 10 \\
\hline Investiga & 118 & Individual & $\begin{array}{l}\text { Realizar el estudio } \\
\text { de una función de } \\
\text { manera no pautada. }\end{array}$ & $\begin{array}{l}\text { Relacionar, mediante la } \\
\text { aplicación de una actividad } \\
\text { anterior, los conceptos } \\
\text { aprendidos. }\end{array}$ & 5 & 10 \\
\hline
\end{tabular}

Fuente: elaboración propia.

Además de las rutinas de pensamiento «Solía Pensar/Ahora Pienso» y «Think/Puzzle/ Explore», cabe destacar las actividades 16 e I10, que tratan de organizar la información de manera global, en el primer caso, con el uso de la herramienta Cmap Cloud, para crear 
mapas conceptuales, y de organizar la información de manera secuencial, en el segundo caso. También se han diseñado cinco actividades cooperativas.

En la parte de la guía denominada «Desarrolla y Reflexiona», se han incluido 27 actividades (véase cuadro 5). En este bloque hay una rutina de pensamiento y dos actividades cooperativas. En ciertos ejercicios los alumnos deben utilizar el mapa conceptual que elaboraron o la tabla de organización secuencial de la información.

\section{Cuadro 5. Relación de actividades de "Desarrolla y Reflexiona»}

\begin{tabular}{|c|c|c|c|c|c|c|}
\hline $\begin{array}{l}\text { Parte de } \\
\text { la guía }\end{array}$ & Actividad & $\begin{array}{l}\text { Tipo de } \\
\text { actividad/ } \\
\text { metodología }\end{array}$ & Desarrollo & $\begin{array}{l}\text { Objetivo de } \\
\text { la actividad }\end{array}$ & Sesión & $\begin{array}{c}\text { Tiempo } \\
\text { estimado (min) }\end{array}$ \\
\hline Desarrolla & D1 & Individual. & $\begin{array}{l}\text { Gráfica de temperatura } \\
\text { de un vaso de agua. }\end{array}$ & $\begin{array}{l}\text { Analizar la gráfica de una } \\
\text { función. }\end{array}$ & 5 & 10 \\
\hline Desarrolla & D2 & Individual. & $\begin{array}{l}\text { Estudio de una gráfica } \\
\text { correspondiente al } \\
\text { índice de la bolsa en } \\
\text { un año. }\end{array}$ & $\begin{array}{l}\text { Analizar la gráfica de una } \\
\text { función. }\end{array}$ & 6 & 5 \\
\hline Desarrolla & D3 & Individual. & $\begin{array}{l}\text { Calcular valores de } \\
\text { ordenadas. }\end{array}$ & $\begin{array}{l}\text { Aplicar la propiedad } \\
\text { de la función explicada } \\
\text { en la actividad } 12 \text {. }\end{array}$ & 6 & 5 \\
\hline Desarrolla & D4 & Individual. & $\begin{array}{l}\text { Practicar con tablas de } \\
\text { valores de deportistas. }\end{array}$ & $\begin{array}{l}\text { Poner en práctica } \\
\text { los conocimientos } \\
\text { adquiridos. }\end{array}$ & 6 & 15 \\
\hline Desarrolla & D5 & $\begin{array}{l}\text { Rutina de } \\
\text { pensamiento } \\
\text { Compara y } \\
\text { Contrasta. }\end{array}$ & $\begin{array}{l}\text { Rutina de pensamiento } \\
\text { sobre las diferentes } \\
\text { formas de presentar } \\
\text { una función. }\end{array}$ & $\begin{array}{l}\text { Analizar las diferentes } \\
\text { maneras de presentar } \\
\text { una función. }\end{array}$ & 6 & 5 \\
\hline Desarrolla & D6 & Individual. & $\begin{array}{l}\text { Escribir la gráfica de } \\
\text { una función definida a } \\
\text { trozos (bolsa). }\end{array}$ & $\begin{array}{l}\text { Aplicar lo aprendido } \\
\text { sobre funciones definidas } \\
\text { a trozos y funciones } \\
\text { lineales, continuidad, } \\
\text { máximos, etc. }\end{array}$ & 6 & 10 \\
\hline Desarrolla & D7 & Individual. & $\begin{array}{l}\text { Estudio de continuidad } \\
\text { de funciones a partir de } \\
\text { su gráfica. }\end{array}$ & $\begin{array}{l}\text { Aplicar el concepto } \\
\text { de «continuidad de } \\
\text { funciones». }\end{array}$ & 6 & 5 \\
\hline
\end{tabular}




\begin{tabular}{|c|c|c|c|c|c|c|}
\hline $\begin{array}{c}\text { Parte de } \\
\text { la guía }\end{array}$ & Actividad & $\begin{array}{l}\text { Tipo de } \\
\text { actividad/ } \\
\text { metodología }\end{array}$ & Desarrollo & $\begin{array}{l}\text { Objetivo de } \\
\text { la actividad }\end{array}$ & Sesión & $\begin{array}{c}\text { Tiempo } \\
\text { estimado (min) }\end{array}$ \\
\hline \multicolumn{7}{|l|}{ 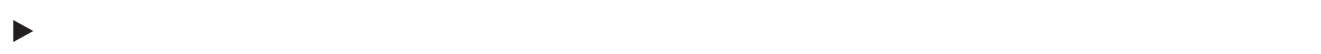 } \\
\hline Desarrolla & D8 & Individual. & $\begin{array}{l}\text { Estudio de continuidad } \\
\text { de funciones a partir de } \\
\text { su expresión analítica. }\end{array}$ & $\begin{array}{l}\text { Aplicar el concepto } \\
\text { de «continuidad de } \\
\text { funciones». }\end{array}$ & 7 & 5 \\
\hline Desarrolla & D9 & $\begin{array}{l}\text { Cooperativa: } \\
\text { absurdos. }\end{array}$ & $\begin{array}{l}\text { Razonar dos frases } \\
\text { sobre continuidad y } \\
\text { discontinuidad. }\end{array}$ & $\begin{array}{l}\text { Analizar cuándo una } \\
\text { función es continua y } \\
\text { cuándo no lo es. }\end{array}$ & 7 & 5 \\
\hline Desarrolla & D10 & Individual. & $\begin{array}{l}\text { Escribir la función que } \\
\text { expresa el espacio que } \\
\text { recorre una persona } \\
\text { caminando. }\end{array}$ & $\begin{array}{l}\text { Aplicar lo aprendido } \\
\text { sobre dominio y rango } \\
\text { de funciones. }\end{array}$ & 7 & 10 \\
\hline Desarrolla & D11 & Individual. & $\begin{array}{l}\text { Estudio del dominio de } \\
\text { funciones a partir de su } \\
\text { expresión analítica. }\end{array}$ & $\begin{array}{l}\text { Aplicar lo aprendido } \\
\text { sobre dominio y rango } \\
\text { de funciones. }\end{array}$ & 7 & 15 \\
\hline Desarrolla & D12 & Individual. & $\begin{array}{l}\text { Estudio del dominio de } \\
\text { funciones a partir de su } \\
\text { expresión analítica. }\end{array}$ & $\begin{array}{l}\text { Aplicar lo aprendido } \\
\text { sobre dominio y rango } \\
\text { de funciones. }\end{array}$ & 8 & 15 \\
\hline Desarrolla & D13 & Individual. & $\begin{array}{l}\text { Estudio del dominio de } \\
\text { funciones a partir de su } \\
\text { expresión analítica. }\end{array}$ & $\begin{array}{l}\text { Aplicar lo aprendido } \\
\text { sobre dominio y rango } \\
\text { de funciones. }\end{array}$ & 8 & 15 \\
\hline Desarrolla & D14 & Individual. & $\begin{array}{l}\text { Estudio de la gráfica de } \\
\text { la temperatura de un } \\
\text { enfermo: crecimiento y } \\
\text { decrecimiento, } \\
\text { máximo, mínimo, etc. }\end{array}$ & $\begin{array}{l}\text { Aplicar lo aprendido } \\
\text { sobre crecimiento } \\
\text { y decrecimiento de } \\
\text { funciones. }\end{array}$ & 8 & 10 \\
\hline Desarrolla & D15 & Individual. & $\begin{array}{l}\text { Curva de glucemia: } \\
\text { máximos y mínimos. }\end{array}$ & $\begin{array}{l}\text { Aplicar lo aprendido } \\
\text { sobre crecimiento } \\
\text { y decrecimiento de } \\
\text { funciones. }\end{array}$ & 8 & 10 \\
\hline Desarrolla & D16 & Individual. & $\begin{array}{l}\text { Estudio de funciones a } \\
\text { partir de su gráfica. }\end{array}$ & $\begin{array}{l}\text { Analizar una función en } \\
\text { todos sus aspectos. }\end{array}$ & 8 & 10 \\
\hline Desarrolla & D17 & Individual. & $\begin{array}{l}\text { Calcular la tasa de } \\
\text { variación media de una } \\
\text { función en diferentes } \\
\text { intervalos. }\end{array}$ & $\begin{array}{l}\text { Aplicar lo aprendido } \\
\text { sobre la tasa de variación } \\
\text { media. }\end{array}$ & 9 & 10 \\
\hline
\end{tabular}




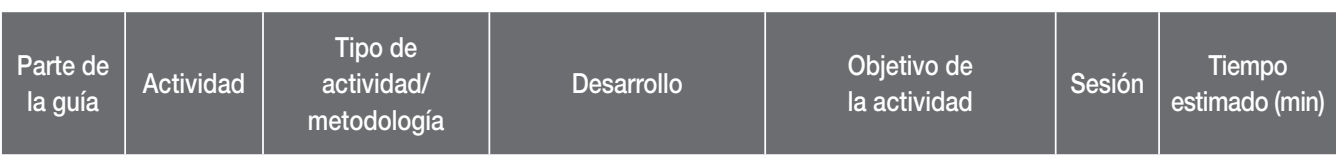

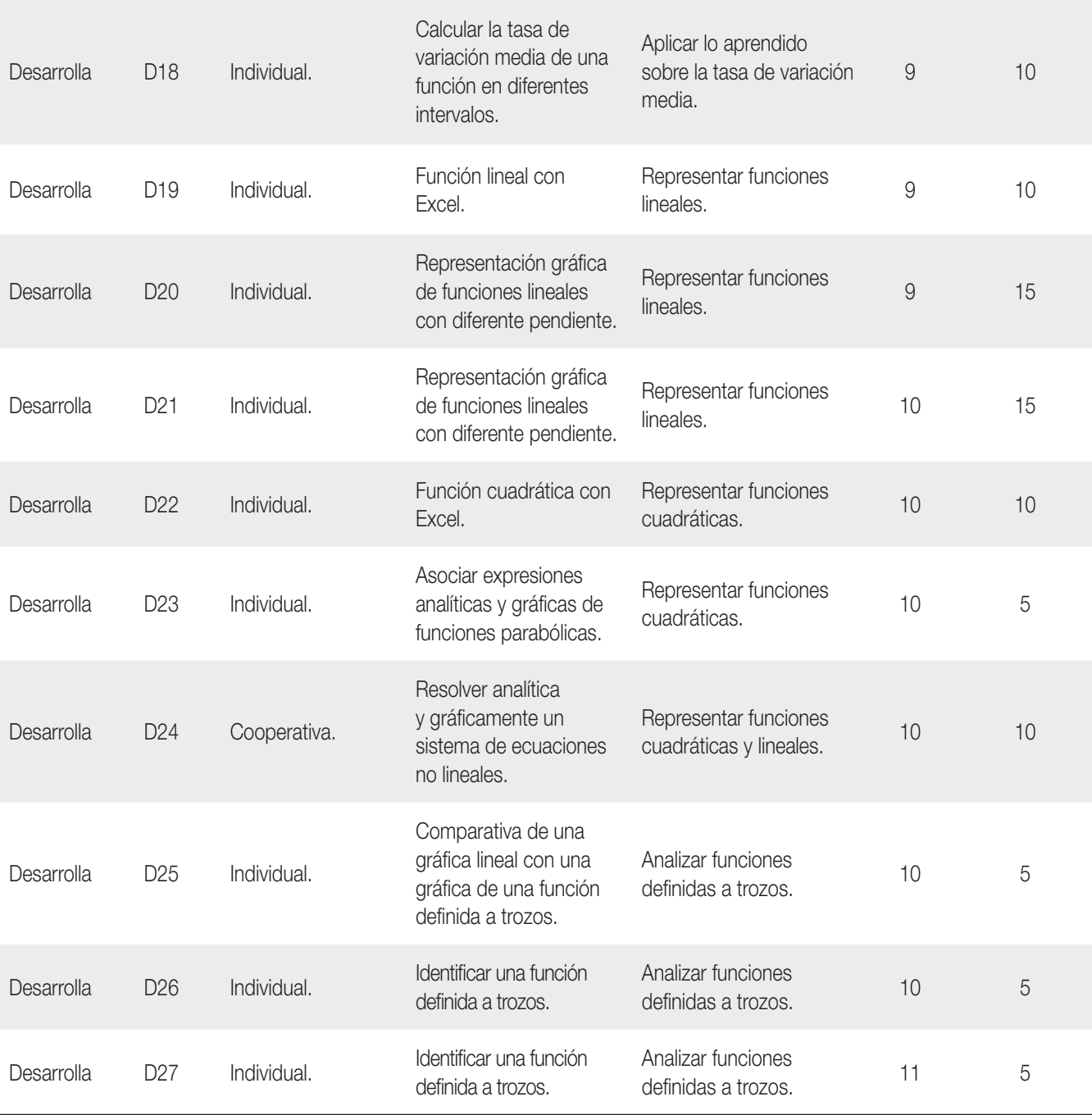

Fuente: elaboración propia.

Y, por último, en la parte de la guía denominada «Relaciona», se ha propuesto la rutina de pensamiento «Relaciona-Amplía-Pregunta» y dos tareas: una cooperativa y otra individual (véase cuadro 6). 
Cuadro 6. Relación de actividades de «Relaciona»

\begin{tabular}{|c|c|c|c|c|c|c|}
\hline $\begin{array}{l}\text { Parte de } \\
\text { la guía }\end{array}$ & Actividad & $\begin{array}{l}\text { Tipo de actividad/ } \\
\text { metodología }\end{array}$ & Desarrollo & $\begin{array}{l}\text { Objetivo de } \\
\text { la actividad }\end{array}$ & Sesión & $\begin{array}{c}\text { Tiempo } \\
\text { estimado ( } \mathrm{min})\end{array}$ \\
\hline Relaciona & $\mathrm{R} 1$ & $\begin{array}{l}\text { Rutina de } \\
\text { pensamiento } \\
\text { Relaciona/Amplía/ } \\
\text { Pregunta. }\end{array}$ & $\begin{array}{l}\text { Rutina de } \\
\text { pensamiento } \\
\text { Relaciona/Amplía/ } \\
\text { Pregunta. }\end{array}$ & $\begin{array}{l}\text { Conectar los } \\
\text { conocimientos de } \\
\text { la unidad. }\end{array}$ & 11 & 10 \\
\hline Relaciona & $\mathrm{R} 2$ & $\begin{array}{l}\text { Taller matemático } \\
\text { cooperativo. }\end{array}$ & $\begin{array}{l}\text { Expresar las funciones } \\
\text { que se corresponden } \\
\text { con el uso de redes } \\
\text { sociales. }\end{array}$ & $\begin{array}{l}\text { Transferir lo aprendido } \\
\text { a una situación } \\
\text { cotidiana. }\end{array}$ & 11 & 20 \\
\hline Relaciona & R3 & Individual. & $\begin{array}{l}\text { Inventar una historia a } \\
\text { partir de una gráfica. }\end{array}$ & $\begin{array}{l}\text { Crear un producto } \\
\text { propio que relacione } \\
\text { lo aprendido en clase. }\end{array}$ & 11 & 10 \\
\hline
\end{tabular}

Fuente: elaboración propia.

La última sección de la guía, «Evalúa», aporta una rúbrica de autoevaluación.

\subsection{Metodología de trabajo}

Antes de llevar esta propuesta al aula se concertó una reunión con la docente que estaba a cargo de impartir las clases de matemáticas al grupo escogido. En dicho encuentro, entre otras cosas, se le explicaron los objetivos de esta intervención. Por otra parte, se ha tratado de adaptar la propuesta al propio estilo de la docente para evitar aumentar la complejidad y que se pudieran distorsionar o perder de vista los principales puntos de interés de la misma.

La metodología requerida para la aplicación en el aula de esta intervención, tal y como se puede ver en la propia guía (Bailén, 2018a), parte del uso de las TIC, dado que cada alumno o grupo de alumnos necesita acceso a internet para poder investigar y seguir el itinerario asignado.

La profesora que ha realizado la intervención en el aula usa Google Classroom habitualmente, con lo cual era un recurso con el que ya contábamos. Así, a los alumnos se les ha asignado el itinerario más adecuado y se les ha pautado las fechas de entrega a través de dicha herramienta.

Cuando los alumnos han comenzado a trabajar con la guía se han encontrado con una metodología diferente en algunos aspectos, aunque otros ya estaban presentes en las prácticas usadas por la docente en el aula. Así, la intervención en el aula con esta guía supone 
utilizar «aprendizaje cooperativo», «fomentar el aprendizaje autónomo», «impulsar la competencia digital»y «emplear el TBL».

Durante el recorrido por la guía, los alumnos han realizado actividades que requerían el manejo de aplicaciones como Geogebra, hojas de cálculo o Cmap Cloud para elaborar mapas conceptuales.

Puntualmente, se han usado explicaciones magistrales.

\subsection{Planificación (ejecución en el año 2018)}

\section{Cuadro 7. Temporización}

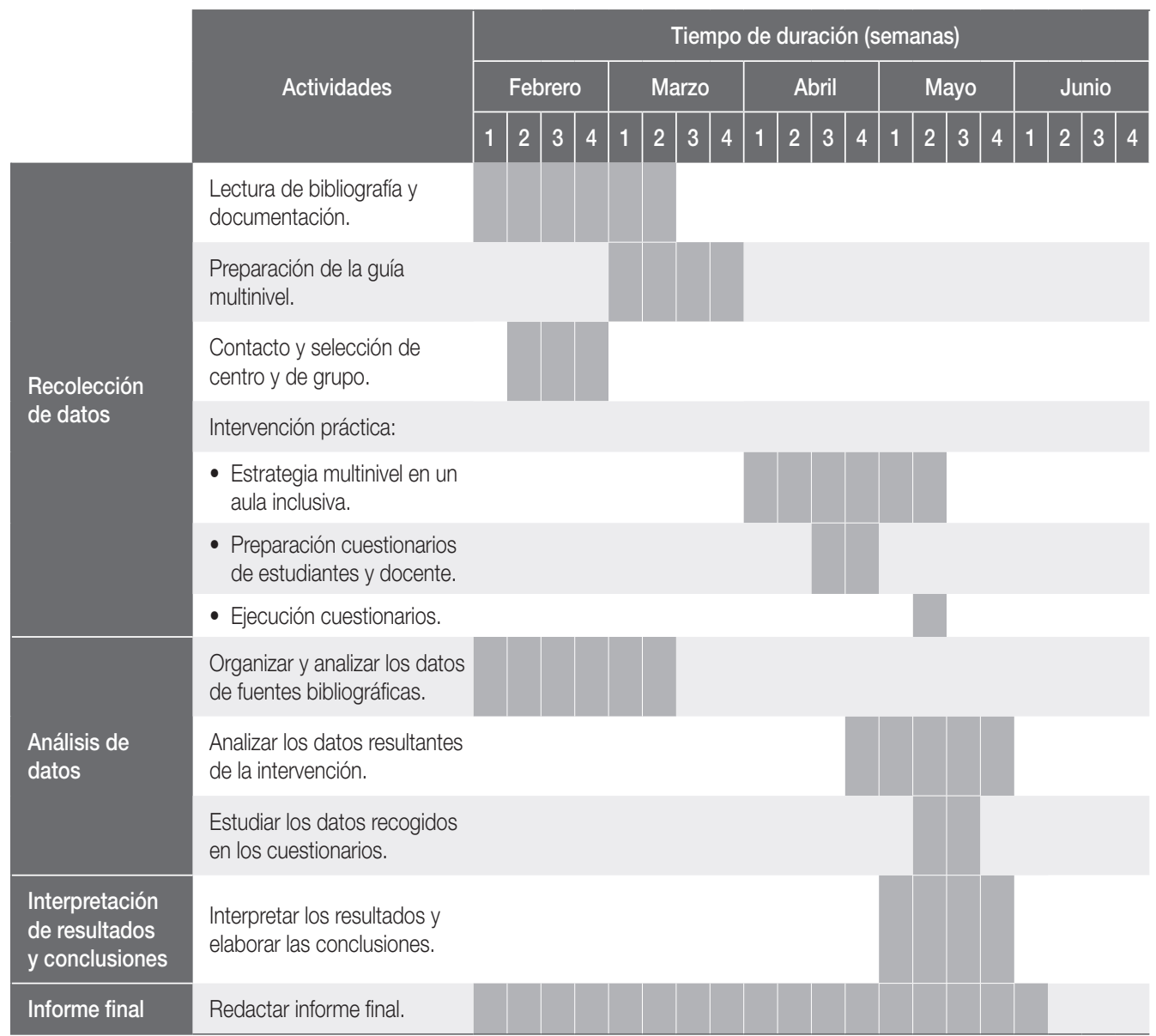

Fuente: elaboración propia. 


\section{Tercera parte. Resultados y conclusiones}

\subsection{Resultados cualitativos y cuantitativos}

Para evaluar los resultados de esta intervención en el aula en términos cualitativos se han elaborado cuestionarios para los alumnos y para la docente que la ha aplicado. Han respondido al cuestionario 43 estudiantes en total.

Nos centraremos aquí en las respuestas dadas por los cinco alumnos con AA. CC. identificados entre los dos grupos por ser este el tema objeto de la presente investigación.

Un primer alumno considera que el nivel de esfuerzo que ha dedicado a completar la guía ha sido alto, que el nivel de conocimientos con el que comenzó a trabajarla era medio y que, cuando acabó, pasó a ser alto. Valora muy positivamente tener los contenidos en formato vídeo y texto, y está de acuerdo en que, gracias a ello, ha aprendido más. Opina que la guía está bien estructurada, que los objetivos están claros, que las actividades con Geogebra y las individuales han sido adecuadas y que, en definitiva, la guía multinivel ha contribuido a mejorar sus conocimientos. No valora positivamente las rutinas de aprendizaje. A la pregunta «¿qué aspectos de esta guía te resultaron más útiles?», el alumno responde que «poder trabajar a su ritmo». Y, en cuanto a cómo mejorarla, sugiere más apoyos visuales y más aplicaciones prácticas de lo aprendido.

Una segunda alumna considera también que el nivel de esfuerzo para completar la guía ha sido alto y que sus conocimientos se han mantenido a un nivel medio. Cree que los contenidos de la guía estaban bien estructurados, pero no considera que estuvieran claros los objetivos de la misma. Al igual que el alumno anterior, valora positivamente tener los contenidos en formato vídeo y texto, pero, al contrario que su compañero, opina que las rutinas de pensamiento sí la han ayudado a aprender. Cree que la guía ha contribuido a mejorar sus conocimientos, pero se muestra neutral en cuanto a la utilidad de las actividades propuestas con Geogebra. En cuanto a los aspectos más útiles de la guía, destaca de nuevo el formato audiovisual de los vídeos, la organización y estructura de la guía en sí y la actividad en la que se pedía realizar un mapa conceptual. Como puntos de mejora señala añadir más ejemplos y propone explicar mejor el resultado esperado de algunas actividades.

De las respuestas del tercer alumno con AA. CC., destacamos que haya valorado muy positivamente tanto las actividades con Geogebra como los contenidos audiovisuales. Sin embargo, como veremos, contrasta con el último alumno, ya que afirma que el nivel de esfuerzo para completarla ha sido muy bajo. De hecho, sugiere, como mejora de la guía, que haya contenidos más avanzados, porque le ha resultado muy sencilla su realización.

Un cuarto alumno cree que, si bien la guía de aprendizaje le ha permitido trabajar autónomamente, los contenidos de la misma no estaban bien estructurados y la página le re- 
sultaba compleja de manejar, por lo que no se siente motivado a usar de nuevo una guía de aprendizaje. Se mantiene neutral en cuanto a la utilidad de las rutinas de pensamiento y al uso de Geogebra, y valora positivamente tener los contenidos en formato vídeo y texto.

El último alumno rechazó desde el inicio el trabajo autónomo y manifestó abiertamente su preferencia por la metodología habitual seguida por la docente. En las respuestas recogidas en el cuestionario, valora el nivel de esfuerzo para completar la guía como muy alto, siendo la suya una de las pocas respuestas que aprecian así este aspecto. La mayoría de los alumnos evalúa el nivel de esfuerzo entre medio y alto. Las 14 preguntas principales del cuestionario las valora neutral o negativamente, salvo la correspondiente a Geogebra, que la valora positivamente, lo que contrasta con la percepción de la docente, según la cual el uso de Geogebra había resultado poco provechoso en términos generales. No obstante, el alumno afirma que lo que más le gustó de la guía fueron las actividades, y lo que menos, que nadie le explicara los contenidos.

La docente, por su parte, considera que el nivel de esfuerzo que los alumnos han dedicado para completar la guía ha sido medio y que, al principio de comenzar a trabajar con la guía, el nivel de habilidades era bajo y, al finalizar, se ha elevado a medio. Evalúa positivamente la guía como herramienta para el aula en cuanto a la organización, planificación, objetivos, carga de trabajo y capacidad para el trabajo autónomo. Está de acuerdo en que sí le gustaría usar otra vez una guía de aprendizaje multinivel. Sin embargo, valora negativamente la utilidad de las actividades con Geogebra. Tampoco puntúa bien la adecuación de las actividades individuales al nivel de conocimiento de los alumnos y no considera que los alumnos con AA. CC. hayan trabajado con especial motivación. Valora de manera neutral que los contenidos estuvieran disponibles en video y en texto, así como las actividades cooperativas, en cuanto a su capacidad para motivar, las rutinas de pensamiento y la adecuación de los itinerarios para atender las necesidades de los alumnos.

Para tener un punto de vista cuantitativo de las conclusiones, a continuación, se aportan resultados de la prueba llevada a cabo por la docente. Se ha contrastado la calificación de los alumnos al concluir otras unidades didácticas trabajadas siguiendo la metodología habitual de la docente con la calificación obtenida siguiendo esta propuesta de intervención.

La docente pidió a los alumnos de ambos grupos completar una prueba individual en la que se les pedía realizar el estudio completo de una función a partir de su gráfica y una representación de una función definida a trozos.

Los resultados de la prueba para los cinco alumnos con AA. CC., en el mismo orden en el que se han citado, han sido $10,10,9,9,10$ y 9,5 .

En uno de los dos grupos, el resto de los alumnos ha obtenido calificaciones entre el 6 y el 9 , con muy buenos resultados, excepto dos alumnos con un 5 y una alumna con un 3 , siendo estos resultados similares a los que se obtienen habitualmente. 
En el otro grupo, la gran mayoría de las calificaciones se sitúan entre el 6 y el 9,5, con muy buenos resultados también, aunque dos alumnos tenían una calificación de 5 , dos alumnos 4,5, dos alumnos 4, dos alumnos 3 y dos alumnos calificaciones por debajo del 2 . A pesar de ser peores resultados que los obtenidos por el primer grupo, la docente afirma que son mejores que los que se obtienen habitualmente.

En cuanto a la planificación prevista para la intervención en el aula, no se pudo cumplir, principalmente por no estar alineada con las actividades extraescolares del centro y por no haber previsto los inconvenientes en el uso de la tecnología, con lo que el trabajo en el aula con la guía multinivel se alargó en el tiempo.

\subsection{Conclusiones y reflexiones personales}

La propuesta de intervención que se ha diseñado supone el empleo de una metodología en el aula que contempla las respuestas educativas citadas en el marco teórico:

- Se ha partido de la estrategia multinivel para desarrollar esta intervención. Así, se han llevado a la práctica los diferentes niveles de la taxonomía de Bloom en sus dos dimensiones: tanto en la dimensión del proceso cognitivo como en la del conocimiento. Además, el uso de estrategias multinivel permite al docente programar itinerarios diferentes para alumnos con distintos niveles curriculares y capacidades.

- A tal propósito se han elaborado una variedad de actividades de niveles distintos que permiten diseñar al menos dos itinerarios para programar a diferentes perfiles de alumnos. En concreto, se han diseñado un itinerario 1 estándar y un itinerario 2 con actividades compartidas y otras de ampliación para los alumnos con AA. CC. También se han producido actividades de refuerzo para usar en caso necesario, aunque no se han incluido de partida en ningún itinerario.

- Además, en el diseño se ha tenido en cuenta el enriquecimiento de los contenidos para adaptarse a los diferentes estilos de aprendizaje y al grado de curiosidad de los alumnos.

- Con este diseño, se permite la aceleración y el aprendizaje autónomo, puesto que el alumno accede a todos los contenidos y actividades, así como a la programación de estos, desde el primer día que se planifica, y se le permite trabajar de manera flexible y autónoma.

- Se han diseñado actividades cooperativas, permitiendo además los agrupamientos flexibles.

- Se han empleado rutinas de pensamiento para llevar a los alumnos a reflexionar sobre su propio proceso de aprendizaje y facilitar así la comprensión de los contenidos. 
- Se han presentado los contenidos en dos formatos diferentes: vídeos (estilo cognitivo-visual) y textos (estilo cognitivo-verbal) para que, o bien los alumnos escojan de qué forma prefieren acercarse a los mismos, o bien usen ambas aproximaciones para enriquecer la investigación de nuevos conceptos.

- Se han incluido actividades que abordan estilos cognitivos diferentes (secuencial y global).

- La metodología usada busca potenciar las competencias para el trabajo autónomo y las competencias social, digital y comunicativa.

Por otra parte, a partir de la observación directa en el aula, realizamos las siguientes reflexiones:

- Es importante disponer de dispositivos de acceso adecuados a la guía multinivel y de una conexión a internet que proporcione un servicio sin interrupciones. Mientras que en el colegio Santa María la Blanca los alumnos usan sus propios ordenadores personales, en la Escuela Ideo no está instaurada esta iniciativa, conocida como Bring Your Own Device, por lo que los alumnos usaron las tabletas del centro o sus propios terminales móviles. En el tiempo pasado en el aula, se observó que las tabletas sí son dispositivos de acceso útiles hasta cierto punto, pero no los smartphones, puesto que la realización de las actividades diseñadas con Geogebra resultaba casi imposible. El acceso a internet también suponía una limitación en determinados momentos.

- Estos inconvenientes provocaban en uno de los alumnos con AA. CC. el deseo de trabajar la guía cuando estuviera en casa y dispusiera de su propio ordenador, puesto que con los medios usados en clase se veía ralentizado. No obstante, el alumno afirmaba avanzar muy rápido. No presentaba ningún problema con el formato y contenido de la propuesta de intervención, pero sí con el tipo de dispositivo utilizado, lo cual reitera la reflexión anterior acerca de la importancia de disponer de los medios adecuados.

- No resulta sencillo que los alumnos comiencen a trabajar de manera autónoma. Un alumno con AA. CC. sentía rechazo al trabajo autónomo. Reclamaba a la profesora que explicara los contenidos porque no le gustaba aprender por su cuenta, ni viendo vídeos ni leyendo los textos, lo cual indica que los estudiantes con AA. CC. no son un colectivo homogéneo y existen diferencias muy notables entre sus estilos de aprendizaje.

- La propuesta de intervención puede ser igual de beneficiosa para el resto de los alumnos; de hecho, muchos de ellos valoraban la guía muy positivamente.

- Es complicado prever itinerarios diferentes sin conocer realmente a los estudiantes. 
En cuanto a las preguntas de investigación planteadas en la introducción de este documento, se les ha ido dando respuesta a lo largo del mismo.

\subsection{Limitaciones y futuras líneas de investigación}

Una de las principales limitaciones de esta investigación la han constituido precisamente los medios tecnológicos. Tanto la disponibilidad de una buena conexión a internet como los dispositivos de acceso adecuados son de crucial importancia en el seguimiento de la guía multinivel y, en este caso, ambos factores han limitado la ejecución.

El uso de la guía multinivel ha sido nuevo tanto para la profesora como para los alumnos, suponiendo un doble nivel de cambio al que tenían que adaptarse. No todos los estudiantes aceptaron el cambio con positivismo. Habría sido conveniente disponer de más tiempo para introducir la guía y hacer a los alumnos partícipes de la propuesta.

Al no haber un tiempo de clase dedicado a las explicaciones y tener que encargarse la docente de resolver dudas, si estas eran numerosas, algunos alumnos podían percibir que nadie atendía sus problemas. La ratio de alumnos en el aula limita el tiempo que la profesora puede dedicar a resolver las dudas de los estudiantes, lo cual es importante para que los alumnos vayan ganando en confianza sobre su propia capacidad para el trabajo autónomo.

Plantear dos itinerarios ha resultado no ser suficiente para cubrir los diferentes niveles de conocimiento de todos los alumnos, incluidos aquellos con AA. CC. Los itinerarios para que sean más acertados deberían plantearse con el conocimiento previo de cuáles son los niveles de los alumnos.

Como futuras aplicaciones o líneas de investigación, cabría plantearse el uso de esta propuesta siguiendo la filosofía de las clases invertidas, puesto que el contenido que hay que trabajar está publicado en un blog accesible desde cualquier ordenador con conexión a internet. Con la edición de los vídeos usando la herramienta EdPuzzle se podría fácilmente completar esta experiencia para llevarla al campo del flipped learning o clase invertida.

Las guías de aprendizaje, tal y como se utilizan en el colegio Santa María la Blanca, siguiendo la metodología EBI, se complementan con unos encuentros profesor-alumno conocidos como «citas de seguimiento», es decir, un momento de aproximación entre el profesor y el alumno de manera individual en el que el docente comprueba la evolución del alumno y su progresión en el trabajo autónomo. En una futura investigación se podría valorar la intervención conjunta mediante guías de aprendizaje y «citas de seguimiento» para comprobar su impacto en la motivación y en el rendimiento de los alumnos con AA. CC.

Del mismo modo, se podrían diseñar intervenciones similares en el campo de otras materias o asignaturas, o en otros niveles educativos, como el de la educación primaria. 
La guía diseñada podría difundirse y darse a conocer entre otros docentes de matemáticas y, al estar publicada en internet, sería fácilmente reutilizable y aplicable sin que necesariamente se tenga que usar pensando en el impacto que genere en los alumnos con AA. CC., puesto que, al tener una base inclusiva, se debería poder utilizar en cualquier aula de matemáticas de $4 .^{\circ}$ de ESO.

\section{Referencias bibliográficas}

Albes, C., Aretxaga, L., Etxebarria, I., Galende, I., Santamaría, A., Uriarte, B. y Vigo, P. (2013). Orientaciones educativas: alumnado con altas capacidades intelectuales. Servicio Central de Publicaciones del Gobierno Vasco. Recuperado de <http://www.euska di.eus/contenidos/informacion/dig_publicaciones_innovacion/es_escu_inc/adjun tos/16_inklusibitatea_100/100012c_Pub_ EJ_altas_capacidades_c.pdf $>$ (consultado en marzo de 2018).

Bailén, E. (2018a). 4. ESO. Funciones. Recuperado de <https://sites.google.com/view/4eso-funciones> (consultado en febrero de 2018).

Bailén, E. (2018b). Curso EBI. Recuperado de <http://tiny.cc/bxk04y> (consultado en febrero de 2018).

Bisquerra, R. y Pérez, N. (2007). Las competencias emocionales. Educación XX1, 10, 61-82. Recuperado de <http://e-spacio.uned.es/ fez/eserv/bibliuned:EducacionXXI-2007 numero10-823/Documento.pdf> (consultado en marzo de 2018).

Blanco, R., Ríos, C. G. y Benavides, M. (2004). Respuesta educativa para los niños con talento. En M. Benavides, A. Maz, E. Castro y R. Blanco (Eds.), La educación de niños con talento en Iberoamérica (pp. 49-60). Santiago de Chile, Chile: Editorial Trineo. Recuperado de <http://sid.usal.es/idocs/ F8/FDO23188/educacion_ni\%C3\%B1os_ talento_iberoamerica.pdf\#page=45> (consultado en abril de 2018).

Bloom, B. S., Engelhart, M. D., Furst, F. J., Hill, W. y Krathwohl, D. R. (1956). Taxonomy of Educational Objectives: Cognitive Domain. Nueva York, EE. UU.: McKay.

BOE (2003). Real Decreto 943/2003, de 18 de julio, por el que se regulan las condiciones para flexibilizar la duración de los diversos niveles y etapas del sistema educativo para los alumnos superdotados intelectualmente. Recuperado de <https:// www.boe.es/boe/dias/2003/07/31/pdfs/ A29781-29783.pdf> (consultado en abril de 2018).

BOE (2014a). Real Decreto 126/2014, de 28 de febrero, por el que se establece el currículo básico de la Educación Primaria. Recuperado de <https://www.boe.es/buscar/act. php?id=BOE-A-2014-2222> (consultado en abril de 2018).

BOE (2014b). Real Decreto 1105/2014, de 26 de diciembre, por el que se establece el currículo básico de la educación secundaria obligatoria y del bachillerato. Recuperado de $<$ https://www.boe.es/boe/dias/2015/01/03/ pdfs/BOE-A-2015-37.pdf> (consultado en abril de 2018).

Bruner, J. S. (1974). Toward a Theory of Instruction. Cambridge, EE. UU.: Harvard University Press. 
Bueno, D. (2017). Neurociencia para educadores. Barcelona, España: Octaedro.

Churches, A. (2001). Bloom's Digital Taxonomy. Recuperado de <http://burtonslifelearning.pb works.com/f/BloomDigitalTaxonomy2001. pdf> (consultado en febrero de 2018).

Collicot, J. (1991). Implementing multi-level instruction: strategies for classroom teachers. En G. Porter y D. Richler (Eds.), Changing Canadian Schools (pp. 192-213). North York, Ontario, Canadá: The Roeher Institute. Recuperado de <https://files.eric. ed.gov/fulltext/ED341224.pdf\#page=192> (consultado en febrero de 2018).

Comes, G., Díaz, E., Luque, A. y Moliner, O. (2008). La evaluación psicopedagógica del alumnado con altas capacidades intelectuales. Revista de Educación Inclusiva, 1(1), 105-117. Recuperado de <http://www.re vistaeducacioninclusiva.es/index.php/ REl/issue/viewlssue/2/1> (consultado en febrero de 2018).

Costa, A. L. y Swartz, R. (2008). ThinkingBased Learning: Promoting Quality Student Achievement in the 21st Century. Nueva York, EE. UU.: Teachers College Press.

Fernández, P. y Extremera, N. (2005). La inteligencia emocional y la educación de las emociones desde el Modelo de Mayer y Salovey. Revista Interuniversitaria de Formación del Profesorado, 19(3), 63-93. Recuperado de <http://www.redalyc.org/ pdf/274/27411927005.pdf> (consultado en marzo de 2018).

Fundación Iruaritz-Lezama (2018a). Proyecto EBI. Recuperado de $<$ http://proyectoebi.es/ innovacion-educativa/> (consultado en abril de 2018).

Fundación Iruaritz-Lezama (2018b). Sistema pedagógico EBI (educación básica interactiva). Formación inicial al profesorado. Recuperado de <https://sites.google.com/ fundacionlezama.es/profesorespractica sebi> (consultado en mayo de 2018).

García, J. M., Abaurrea, V. e Iriarte, G. (1997). Alumnado con sobredotación intelectual/ altas capacidades: orientaciones para la respuesta educativa. Gobierno de Navarra. Departamento de Educación y Cultura. Recuperado de <http://sid.usal.es/idocs/ F8/FDO26800/altas_capacidades.pdf> (consultado en marzo de 2018).

Gardner, H. (1995). Reflections on multiple intelligences: Myths and messages. Phi Delta Kappan, 77(3), 200-209. Recuperado de $<$ https://canvas.stanford.edu/cour ses/73326/files/2177319/download?verifi er=E2WcnOHVDzAth5W9kJrRkziZeo5uH UnBqVkYYgwV\&wrap=1> (consultado en febrero de 2018).

Gardner, H. (2003). Multiple Intelligences After twenty Years. Recuperado de <http://www. kvccdocs.com/FYE125/lesson-resources/ Gardiner-MI-Article.pdf> (consultado en febrero de 2018).

Gardner, H. (2005). Inteligencias múltiples: la teoría en la práctica. Barcelona, España: Paidós.

Garrido, I. (13 de marzo de 2007). Niños y niñas superdotados. Cómo afrontar su infelicidad. La Vanguardia. Recuperado de $<$ http://confederacionceas.altascapacida des.es/comoafrontar.pdf> (consultado en abril de 2018)

Goleman, D. (1995). Emotional Intelligence. Nueva York, EE. UU.: Bantam Books.

González, M. ${ }^{a}$ T. (2002). Agrupamiento de alumnos e itinerarios escolares. Cuando las apariencias engañan. Educar, 29, 167-182. Recuperado de <http://www.raco.cat/index. php/Educar/article/viewFile/20760/20600> (consultado en abril de 2018).

Kilpatrick, W. H. (1918). The Project Method: The Use of the Purposeful Act in the Educa- 
tive Process. Teachers College. Columbia University. Recuperado de <https://archive. org/details/projectmethodus00kilpgoog> (consultado en febrero de 2018).

López, O., Prieto, M. ${ }^{a}$ D. y Hervás, R. M. (1998). Creatividad, superdotación y estilos de aprendizaje: hacia un modelo integrador. Faisca: Revista de Altas Capacidades, 6, 86-108. Recuperado de <https://dialnet.uni rioja.es/servlet/articulo?codigo=2476212> (consultado en febrero de 2018).

Marina, J. A. (1993). Teoría de la inteligencia creadora. Barcelona, España: Anagrama.

Marina, J. A. (2012). La inteligencia ejecutiva. Barcelona, España: Ariel.

Marina, J. A. (2015). El talento de los adolescentes. Barcelona, España: Ariel.

Marland, S. P. (1971). Education of the Gifted and Talented. Volume I: Report to the Congress of the United States by the US Commissioner of Education. Recuperado de <https://files.eric.ed.gov/fulltext/ ED056243.pdf> (consultado en febrero de 2018).

Martín, J. (Coord.). (2000). Alumnos precoces, superdotados y de altas capacidades. Madrid, España: Ministerio de Educación. Recuperado de <https://sede.educacion. gob.es/publiventa/alumnos-precoces-super dotados-y-de-altas-capacidades/educacionespecial-y-compensatoria/8073> (consultado en abril de 2018).

Martín, R. M. y Vargas, M. (2014). Altas capacidades en la escuela inclusiva. Revista Padres y Maestros/Journal of Parents and Teachers, 358, 39-43. Recuperado de $<$ http://revistas.upcomillas.es/index.php/ padresymaestros/article/view/4087Z> (consultado en mayo de 2018).

Mayer, J. D. y Salovey, P. (1993). The intelligence of emotional intelligence. Intelligence, $17,433-442$.
Mayer, J. D., Caruso, D. y Salovey, P. (1999). Emotional intelligence meets traditional standards for an intelligence. Intelligence, 27, 267-298.

Mayer, J. D., Caruso, D. y Salovey, P. (2000). Models of emotional intelligence. En R. Sternberg (Ed.), Handbook of Intelligence (pp. 396-420). Nueva York, EE. UU.: Cambridge.

Mayer, J. D., Caruso, D. y Salovey, P. (2004). Emotional intelligence: theory, findings, and implications. Psychological Inquiry, 15, 197-215.

Mayer, J. D., Salovey, P. y Caruso, D. R. (2007). Mayer-Salovey-Caruso emotional intelligence test (MSCEIT). User's Manual. Toronto, Canadá: MHS.

Mayer, J. D. y Salovey, P. (1997). What is emotional intelligence? En P. Salovey y D. J. Sluyter (Eds.), Emotional Development and Emotional Intelligence: Implications for Educators (pp. 3-31). Nueva York, EE. UU.: Basic Books.

Mirandés, J. de. (2001). La teoría de Joseph Renzulli, en el fundamento del nuevo paradigma de la superdotación. Recuperado de <http://confederacionceas.altas-capa cidades.net/L_T_J_R1.pdf> (consultado en marzo de 2018).

Mirandés, J. de. (2004). Los estilos de aprendizaje de los alumnos superdotados. Primer Congreso Internacional de Estilos de Aprendizaje. Madrid, 5, 6 y 7 de julio. Recuperado de <http://altascapacidadescse.org/ Los\%20Estilos\%20de\%20Aprendizaje\%20 de\%20los\%20Alumnos\%20Superdotados PonenciaUNED.pdf> (consultado en marzo de 2018).

Mora, F. (2014). Neuroeducación. Madrid, España: Alianza Editorial.

OMC, Consejo General de Colegios Oficiales de Médicos de España y Consejo Superior de 
Expertos en Altas Capacidades (2014). Guía científica de las altas capacidades. Recuperada de <http://altascapacidadescse.org/ shop/Guia\%20Cient\%C3\%ADfica\%20 ICP10.pdf> (consultado en marzo de 2018).

Renzulli, J. S. (2004). Introduction to Identification of Students for Gifted and Talented Programs. Recuperado de <https:// us.corwin.com/sites/default/files/upmbinaries/7027_renzulli_intro.pdf> (consultado en febrero de 2018).

Salovey, P. y Mayer, J. D. (1990). Emotional intelligence. Imagination, Cognition, and Personality, 9, 185-211.

Sternberg, R. (1985a). La teoría triárquica de la inteligencia: comprender el autogobierno mental. Recuperado de <https://www. academia.edu/4989396/Teor\%C3\%ADa_ tri\%C3\%A1rquica_de_la_inteligencia_ de_Sternberg $>$ (consultado en febrero de 2018).

Sternberg, R. (1985b). Beyond IQ: a triarchic theory of human intelligence. Nueva York, EE. UU.: Cambridge University Press.

Sternberg, R. y O'Hara, L. (2005). Creatividad e inteligencia. CIC. Cuadernos de Información y Comunicación, 10, 113-149. Recuperado de <http://www.redalyc.org/articulo.oa ?id=93501006 $>$ (consultado en marzo de 2018).

Swartz, R., Costa, A., Beyer, B., Reagan, R. y Kallick, B. (2007). Thinking Based Learning. Norwood, EE. UU.: Christopher-Gordon.

Tomlinson, C. A. (1999). Mapping a route toward differentiated instruction. Educational Leadership, 57(1), 12-16. Recuperado de <https://cpb-us-west-2-juc1ugur1qwq qqo4.stackpathdns.com/blog.elanco.org/ dist/a/853/files/2015/01/Mapping-aRoute-Towards-Differentiated-Instruction -1 synvr0.pdf> (consultado en febrero de 2018).
Torrego, J. C. (Coord.). (2011). Alumnos con altas capacidades y aprendizaje cooperativo: un modelo de respuesta educativa. Madrid, España: Fundación SM. Recuperado de <http://www.fundacionpryconsa. es/media/Altas_capacidades_y_aprendi zaje_cooperativo.pdfs (consultado en mayo de 2018).

Torrego, J. C., Monge, C., Pedrajas, M. L. y Martínez, C. (2015). Formación del profesorado en aprendizaje cooperativo y alumnos con altas capacidades: un enfoque inclusivo. Revista Latinoamericana de Educación Inclusiva, 9(2), 91-110. Recuperado de <https://dialnet.unirioja.es/servlet/ articulo?codigo $=5504538$ (consultado en mayo de 2018).

Tourón, J. (17 de febrero de 2006). El rendimiento de los superdotados. La Vanguardia. Recuperado de <http://confederacionceas. altascapacidades.es/El\%20rendimiento\%20 de\%20los\%20superdotados\%20(1).html> (consultado en abril de 2018).

Tourón, J. (2012). El modelo de los tres anillos. Recuperado de <https://www.javiertouron. es/el-modelo-de-los-tres-anillos/> (consultado en abril de 2018).

Tourón, J. (2015). ¿Cuántos alumnos de alta capacidad hay en España? Unas cifras para la reflexión. INED 21. Recuperado de $<$ https://ined21.com/cuantos-alumnosde-alta-capacidad-hay-en-espana-unascifras-para-la-reflexion/> (consultado en febrero de 2018).

Tourón, J. (2016). La taxonomía de Bloom: ¿hablamos? Recuperado de <https://www. javiertouron.es/la-taxonomia-de-bloomhablamos-12/> y <https://www.javiertouron. es/la-taxonomia-de-bloom-hablamos-22/> (consultado en abril de 2018).

Tourón, J. (2017). Metas reales de aprendizaje. La taxonomía de Bloom. INED 21. Recuperado de <https://ined21.com/metas-reales 
-de-aprendizaje-taxonomia-de-bloom/> (consultado en abril de 2018).

Tourón, J. (2018). Alumnos de alta capacidad: ¿es posible definirlos? Recuperado de $<$ https://www.javiertouron.es/alta-capa cidad-definicion/> (consultado en abril de 2018).

Tourón, J., Peralta, F. y Repáraz, C. (1996). La aceleración como estrategia educativa para alumnos de alta capacidad académica: concepto, modalidades y evaluación de resultados. Revista Española de Pedagogía, 203, 5-39. Recuperado de <http:// dadun.unav.edu/handle/10171/18770> (consultado en abril de 2018).

Vergara, J. J. (2015). Aprendo porque quiero: el aprendizaje basado en proyectos $(A B P)$, paso a paso. Madrid, España: SM.

Vizcaíno, I. (2016). El cambio que revolucionará los deberes. En E. Bailén, Cómo sobrevivir a los deberes de tu hijo (pp. 187203). Barcelona, España: Planeta.

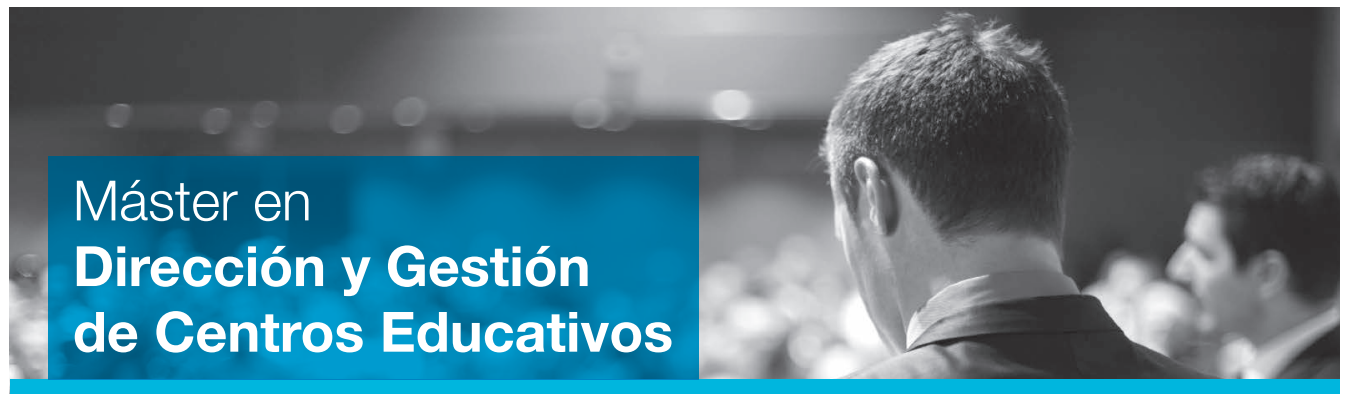

Este máster oficial [60 créditos ECTS] tiene una duración normal de 12 meses.

Los miembros de equipos directivos y los gestores de instituciones educativas encuentran en la actualidad una necesidad apremiante de formación que les habilite para dar una adecuada respuesta a las complejas situaciones que acontecen diariamente en sus lugares de trabajo. Las demandas que la sociedad actual realiza a las instituciones educativas exigen una constante renovación tanto de los centros educativos como de la formación de los profesionales que trabajan en ellos.

Dirigido a: Titulados universitarios que quieran especializarse en el ámbito de la dirección y gestión de centros educativos. Este programa formativo no exige una experiencia previa en la materia, sino que pretende proporcionar a los participantes una formación completa para la dirección y gestión de los centros de forma progresiva y eficaz.

Objetivos: Capacitar a profesionales de primer nivel para el ejercicio eficaz de la función directiva y de gestión de centros educativos. Para ello, el máster pretende dotar al alumno de las competencias y herramientas necesarias para el trabajo en un equipo multidisciplinar de profesionales, así como para promover la calidad y la innovación dentro del sistema educativo. 


\section{Nuestro sistema de enseñanza}

\section{/ Adaptados al mercado laboral. Adaptados a ti}

\section{Mucho más que una universidad a distancia}

La Universidad a Distancia de Madrid, UDIMA, es una institución educativa pensada y diseñada para cubrir las necesidades de las personas del siglo XXI: profesionales que demandan una universidad abierta y flexible, y que permita compatibilizar el estudio con las peculiaridades de cada estudiante, que buscan obtener una titulación universitaria reconocida oficialmente y de prestigio, adaptada a Europa y en contacto con el mundo de la empresa, y que facilite, además, una buena inserción laboral o mejore la que ya se posee.

\section{Campus virtual y sistema de evaluación}

El proceso de aprendizaje se desarrolla a través de las aulas virtuales de la universidad. Los estudiantes establecen una comunicación directa con sus profesores a través de los foros, el teléfono y otras herramientas telemáticas, como las clases en videoconferencia. Un sistema de evaluación continua, que utiliza las últimas herramientas tecnológicas en el ámbito de la didáctica, nos permite desarrollar una metodología activa que ayuda a nuestros estudiantes a «aprender haciendo».

\section{Profesorado}

En la UDIMA, la actuación de los docentes no se limita a la enseñanza, sino que también son «guías y facilitadores». La realización de un seguimiento académico pormenorizado y la personalización de la acción docente hacen de la UDIMA una comunidad de aprendizaje centrada en las personas.

\section{Materiales de enseñanza}

Nuestra editorial técnica se encarga de diseñar materiales específicamente creados para el aprendizaje online. Además, utilizamos recursos audiovisuales y material complementario de todo tipo que permiten aprovechar al máximo la experiencia formativa.

\section{Actividades de aprendizaje}

Los estudiantes van adquiriendo conocimientos a través de distintas actividades, tanto individuales como en grupo, para ir afianzando los contenidos.

\section{Test de autoevaluación}

Pruebas de evaluación online tipo test que, a modo de cuestionarios de autocomprobación, permiten que el estudiante pueda constatar los conocimientos adquiridos en el estudio previo de las unidades didácticas correspondientes.

\section{Actividades de evaluación continua}

Este tipo de actividades didácticas son pruebas de evaluación de tipo práctico: casos y trabajos basados en la búsqueda de información, el análisis de situación y la realización y presentación de informes.

\section{Exámenes presenciales}

Los exámenes finales semestrales son presenciales y con carácter obligatorio. Este tipo de prueba de evaluación permite verificar el cumplimiento de los objetivos de aprendizaje previstos en cada asignatura.

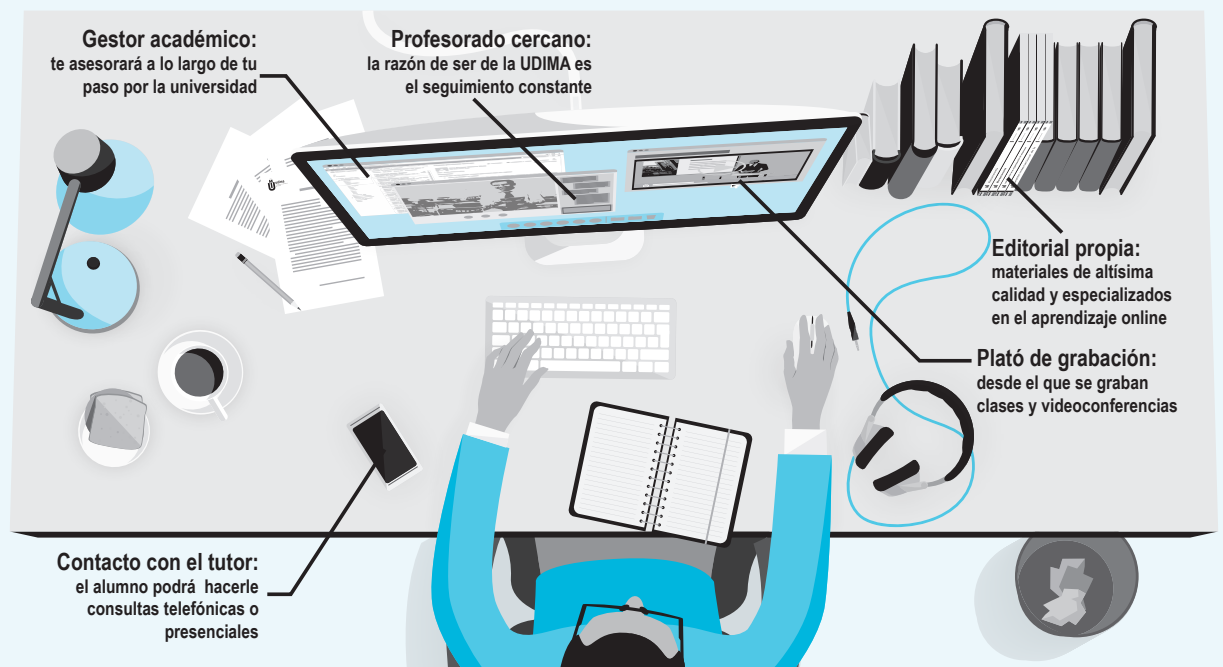




\section{¿Qué nos diferencia de otras Universidades online?}

La Universidad a Distancia de Madrid, UDIMA, está diseñada para cubrir las necesidades de las personas del siglo XXI: profesionales que demandan una titulación universitaria reconocida oficialmente y de prestigio, adaptada a Europa y en contacto con el mundo de la empresa, y que facilite, además, una buena inserción laboral o mejore la que ya se posee.

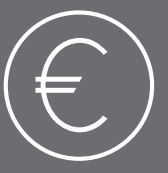

Materiales incluidos

El precio del crédito incluye todos los materiales necesarios para estudiar en la Universidad online más cercana. En la UDIMA siempre sabes lo que pagas. Sin sorpresas.
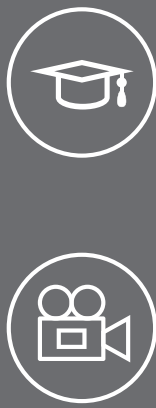

\section{Profesores especialistas}

Los profesores de la UDIMA no solo son expertos en la materia, sino también especialistas en la enseñanza online.
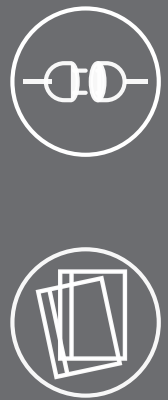

\section{Plató de grabación}

Contamos con un plató con las últimas tecnologías audiovisuales que nos permiten darte la máxima calidad en las clases en videoconferencia.
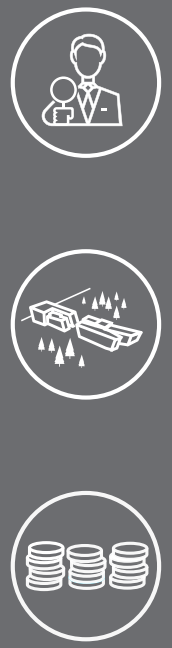

\section{Tutor personal}

Al inicio del Grado se te asignará un tutor personal que te acompañará todo el tiempo que estés con nosotros para que nunca te sientas solo.

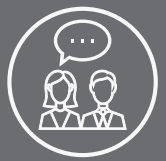

\section{Materiales adaptados}

Contamos con una Editorial propia que desarrolla los libros y carpetas especialmente diseñados para el aprendizaje online, que te llegarán a casa al principio de cada semestre.

\section{Encuentros presenciales}

Realizamos talleres, conferencias y prácticas presenciales voluntarias que amplían el contenido de las asignaturas.

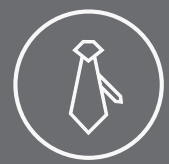

\section{Contacto con empresas}

Nuestra Bolsa de Trabajo y

Emprendedores te ofrece asesoría individualizada para que puedas potenciar tus cualidades y posicionarte como quieras en el mercado laboral.

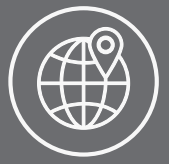

\section{Campus propio}

Podrás venir a ver a los profesores a las instalaciones de Villalba. Nuestro campus ha ganado el prestigioso Premio Inmobiliario Internacional Asprima-SIMA.

\section{Pago fraccionado}

Para que el dinero no sea un impedimento, te ofrecemos la posibilidad de realizar el pago fraccionado o a través de financiación bancaria. Que estudiar sea tu única preocupación.

\section{Sedes de examen}

Estamos cerca de ti. Además de alrededor de toda España, contamos con sedes en Europa, Asia y

América, con especial relevancia en Latinoamérica.

\section{Convocatoria en septiembre}

No es fácil compaginar el estudio con la vida personal y profesional. Por eso tenemos una convocatoria extra en septiembre. Tienes dos oportunidades al año de aprobar cada asignatura. 


\section{Sedes de examen}

\section{/ Dónde puedes examinarte}

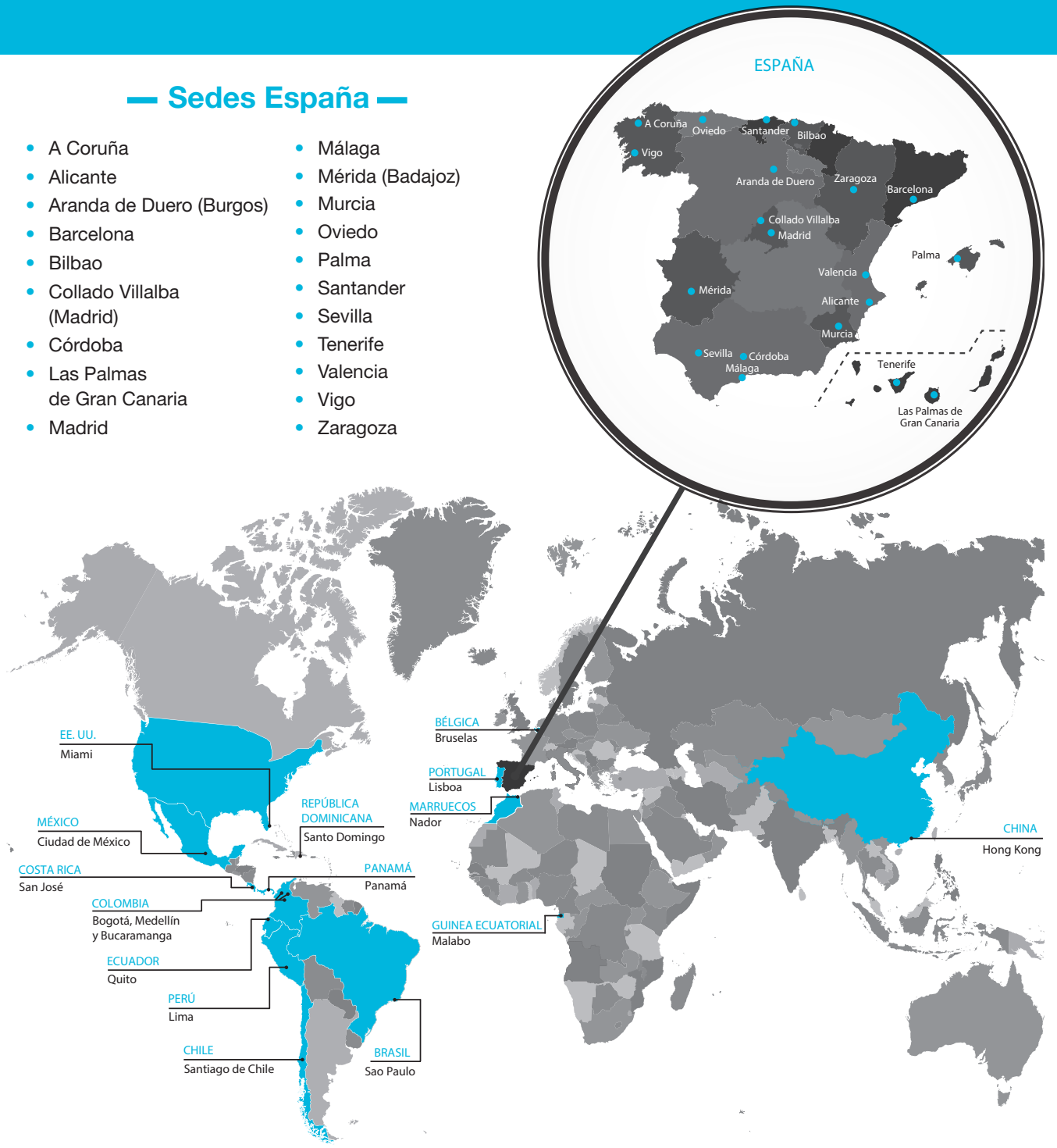

\section{- Sedes extranjero -}

- Bélgica (Bruselas)

- Brasil (Sao Paulo)

- Chile

(Santiago de Chile)

- China (Hong Kong)
- Colombia (Bogotá, Medellín y

Bucaramanga [sede no permanente])

- Costa Rica (San José)
- Ecuador (Quito)

- México (Ciudad de México)

- EE. UU. (Miami)

- Panamá (Panamá)
- Perú (Lima)

- Portugal (Lisboa [sede no permanente])

- República Dominicana (Santo Domingo) 